\title{
REGIONAL AND SECTORAL EVIDENCE OF THE MACROECONOMIC EFFECTS OF LABOR REALLOCATION: A PANEL DATA ANALYSIS ${ }^{\star}$
}

\author{
Dimitrios BaKas ${ }^{\mathrm{a}, \mathrm{f}} \quad$ TheOdore PANAgiotidis $^{\mathrm{b}, \mathrm{f}} \quad$ GiAnluigi Pelloni $^{\mathrm{c}, \mathrm{d}, \mathrm{e}, \mathrm{f}}$
}

\author{
${ }^{a}$ Nottingham Trent University, UK \\ ${ }^{\mathrm{b}}$ University of Macedonia, Greece \\ ${ }^{\mathrm{C}}$ University of Bologna, Italy \\ ${ }^{\mathrm{d}}$ Wilfrid Laurier University, Canada \\ ${ }^{\mathrm{e}}$ Johns Hopkins University, SAIS Bologna Center, Italy \\ ${ }^{\mathrm{f}}$ Rimini Centre for Economic Analysis (RCEA), Italy
}

March 22, 2016

\begin{abstract}
This paper revisits the sectoral shifts hypothesis by examining unemployment fluctuations for 48 U.S. states over the period 1990:01-2011:12. We develop a panel approach that incorporates dynamics, parameter heterogeneity, aggregate factors and cross-sectional dependence. Our findings provide support for a positive and significant effect of the employment dispersion index on unemployment. This outcome is robust under alternative specifications and measures of employment dispersion. The empirical evidence corroborates the presence and relevance of cross-sectional dependence and heterogeneity among states. The results show that, once unobserved common factors and cross-state heterogeneity are taken into account, labor reallocation has a significant effect on unemployment that is half the size of the estimate when cross sectional dependence is not taken into account. (JEL E24 E E32 $\cdot J 21 \cdot R 23 \cdot$ C23)
\end{abstract}

\footnotetext{
*Acknowledgments: We would like to thank the Co-Editor and an anonymous referee for their constructive comments and helpful suggestions. We would also like to thank Karim Abadir, Richard Baillie, Ramazan Gençay, Jerzy Konieczny, Angelo Melino, Roberto Patuelli, Hashem Pesaran, Vasilis Sarafidis and Thanasis Stengos for their useful comments and suggestions on earlier versions of this work. Also we would like to thank Markus Eberhardt for kindly providing his STATA routines. Finally, we are grateful to the participants of the 2nd Time Series Workshop of the Rimini Center for Economic Analysis. All remaining errors are our own.

Bakas: Nottingham Trent University, Nottingham Business School, Division of Economics, Burton Street, NG1 4BU, Nottingham, UK, E-mail: dimitrios.bakas@ntu.ac.uk

Panagiotidis: University of Macedonia, Department of Economics, 156 Egnatia Street, 54006, Thessaloniki, Greece,

E-mail: tpanag@uom.edu.gr (Corresponding Author)

Pelloni: University of Bologna, Department of Economics, Via Anghera 22, 47900, Rimini, Italy,

E-mail: gianluigi.pelloni@unibo.it
} 


\section{INTRODUCTION}

There has been considerable discussion over sectoral shifts (shifts in sectors employment demand) as a triggering force of unemployment fluctuations in the U.S. (see Elsby et al., 2010; Estevão and Tsounta, 2011; Chen et al., 2011; Diamond, 2013). In a recent work, Dao et al. (2014) compares regional labor market adjustments in the US and Europe and find that dispersion has narrowed across regions in the US. Lilien's (1982) seminal paper on sectoral shifts started a cottage industry of studies which has been developing along several dimensions and a variety of econometric methodologies. Following the pioneering efforts of Medoff (1983), Neumann and Topel (1991) and Blanchard and Katz (1992), we bring together both the sectoral and regional dimensions of intersectoral reallocations and explore the impact of a purged measure of labor reallocation on unemployment using an extensive panel dataset for the United States spanning more than two decades.

Panel data analyses in the field of sectoral shifts have mostly relied on fixed effects estimators and have neglected recent advances in panel data econometrics (see Gallipoli and Pelloni, 2008; 2013, section 5 and in particular Table 2). This oversight is a startling omission given the importance of heterogeneity, spillover effects and common factors in the analysis of the macroeconomic effects of labor reallocation for the U.S. states. It is the purpose of this paper to re-examine this state of the art by extending previous research in three directions. First we employ up-to-date dynamic panel data techniques. The relevant novel aspects of this article include recent developments in panel data econometrics concerning dynamics, heterogeneity and cross-sectional dependence which, to the best of our knowledge, have never been applied before in this field and certainly not in this context.

Second, we have built an extensive dataset for U.S. states. The size of our panel dataset alleviates the problem of degrees of freedom which impaired previous studies. Finally, since in recent years most sectoral panel studies have focused on wages, our approach re-focuses on the unemployment, as in the early analyses of Neumann and Topel (1991) and Parker (1992). Our model specification is akin to that used by Mills et al. (1995) and employs a purged Lilien's type dispersion measure instead of Neumann and Topel's proxy.

The remainder of the paper is organized as follows. Section II discusses the paper background and motivation. Section III provides the econometric model and estimation methodology. Section IV presents the data and provides a preliminary data analysis. Section V reports the empirical results 
and Section VI, concludes.

\section{LABOR REALLOCATION AND REGIONS}

A perpetual reallocation of jobs and workers lies beneath labor market activities while an economy is growing. ${ }^{1}$ Though much reallocation may take place within each individual sector, it is also true that declining sectors are destroying more jobs than they are creating while the opposite is happening in expanding sectors. Differences in job creation and destruction within sectors imply intersectoral movements of workers. ${ }^{2}$ The Sectoral Shifts Hypothesis (SSH) claims that workers move from declining sectors to expanding sectors and that such an activity requires time and entails a temporary increase in unemployment (Lilien, 1982, for surveys of the literature see Gallipoli and Pelloni (2008; 2013))..$^{3}$

The SSH has been often analysed by looking at the reallocation of workers across sectors at country level. Some researchers (Medoff, 1983; Neumann and Topel, 1984; 1991) investigated the regional component instead of focusing only on the aggregate level. This analytical extension provides a more accurate and informative view of the phenomenon and its underlying dynamics. Draghi (2014) reminds us that aggregation can conceal the heterogeneity that exists in the data. Taking into account the regional dimension alongside the sectoral one, allows us to observe how changes in the industrial composition of labor demand affect different regions, how these local effects are interrelated and how they could reverberate at national level.

If Lilien (1982) led the revival of the SSH and the reallocation hypothesis (RH), ${ }^{4}$ Medoff (1983) steered their courses towards the regional dimension. He analysed differences in labor market imbalances in the North-East-Atlantic and South-West-Pacific U.S. states. Using alternative definitions of the Beveridge curve (the relationship between unemployment and vacancies) and a battery of reduced form equations, he could relate Beveridge curve(s) shifts to the changing labor conditions across areas for the pre- and post- 1973 periods. Medoff's evidence favors labor market imbalances across time and

\footnotetext{
${ }^{1}$ Unemployment is an essential feature in the process of creative destruction and growth. Schumpeter (1976, ch. 7) advanced the notion of creative destruction which was developed in its contemporary form by Aghion and Howitt (1992). The reallocation underlying labor market workings has been pioneered by Davis and Haltiwanger (1992, see also Davis et al. (2006; 2012)) who have been building on an early contribution by Lilien (1982).

${ }^{2}$ Furthermore, existing evidence (Hamermesh et al., 1996; Abowd et al., 1999; Burgess et al., 2000) suggests that worker turnover (hiring plus separation) is about two-three times the size of job reallocations (creations plus destructions).

${ }^{3}$ It could also involve an increase in long term unemployment if a sufficiently large share of "movers" will not be able to find employment in the expanding sectors for lack of skills or other reasons.

${ }^{4}$ Davis (1987) points out that Ricardo (1891, ch. 19) was already aware of the intuition behind the RH. In this perspective Lilien's contribution has been leading a revival.
} 
regions and suggests a high structural unemployment. Inevitably the analytical framework reflects the state of econometrics of its time and has been superseded since then. Nevertheless Medoff's work has brought to the fore the importance of regional productive structure and its potential impact vis-a-vis large economic restructuring.

Neumann and Topel $(1984 ; 1991)$ brought the analysis a step forward and explored simultaneously the geographical and sectoral dimensions using a panel data approach. They tested whether demand uncertainty, diversification and sectoral shifts are important determinants of equilibrium unemployment differentials among labor markets for the period 1948-1981. Neumann and Topel estimated alternative specifications of their benchmark model pooled across states and over time using fixed effects estimators (as dictated by the then prevailing state of the art). The emerging outcomes bear out that regional differences in unemployment are quite large and persistent over time. Permanent sectoral demand shifts are significant determinants of unemployment but their impact is modest relative to the typical unemployment fluctuations.

The regional analysis of Neumann and Topel (1984; 1991), contrary to Medoff (1983), cannot fully corroborate the relevance of sectoral shifts. Two factors may affect negatively Neumann and Topel's analysis. First, their dispersion index may belittle the role of allocative shocks (Shaw, 1989). Second, because of the fixed effect estimator, their outcomes could be subject to a significant bias, occurring when parameter heterogeneity and cross-section dependence are ignored. While the robustness of their dispersion index could be tested using different measures of dispersion, the second problem was untreatable at the time of Neumann and Topel's article publication as it involved developments in econometrics not yet available.

Parker (1992) studied the unemployment effects of sectoral shifts by controlling for several marketdistortions and changes in the demographic composition of the labor force. By examining the relative explanatory power of alternative measures of intersectoral and interregional dispersion indexes, he could bear out the significant impact of both interindustry and geographical employment shifts on unemployment. These effects are magnified when sectors and regions are broadly defined.

Subsequent panel data analyses in this field have mostly focused on the sectoral and not the regional dimension, and have also been more concerned with wage differentials than unemployment changes. Methodologically they are restricted to fixed effects estimators (Shaw, 1989; Keane, 1991; Keane and Prasad, 1996). Recently at regional level, the fixed effects approach of Estevão and Tsounta 
(2011) corroborate the links between state-level unemployment rates changes, skill mismatches and the housing market performance (even after controlling for cyclical effects).

De Serres et al. (2002) upgraded the sectoral panel data methodology. They study the share of wages in the total income for five European countries and the U.S. using pooled time-series and cross-section data and imposing partial heterogeneity by means of the Pesaran et al.'s (1999) Pooled Mean Group (PMG) estimator. Short-run coefficients could differ across groups but at the same time the long-run coefficients are constrained to be identical. The authors conclude that the persistent trend decline in the aggregate real wage share in the 1980's and 1990's is not necessarily only the effect of a pervasive wage moderation but could also reflect changes in sectoral composition. Besides the wages focus, the methodological improvement is limited. Fixed effect approaches, while convenient, substantially restrict the nature of heterogeneity and fail to take into account potential common factors effects across individuals and the potential interdependence of the individual units (Baltagi (2008), chapter 12; Chudik and Pesaran (2015b)). De Serres et al. (2002) extends the methodology to the PMG estimator, which is only an intermediate heterogeneous estimator.

Simon (2014) explored the relationship between unemployment and sectoral change across U.S. states during the Great Recession using Neumann and Topel's (1991) dispersion measure in a random effects model. Simon's findings stress the importance of structural factors and show that sectoral changes can account for an increase between 34 and 61 percent in median state unemployment between 2007 and 2009. Notwithstanding its methodological improvement, Simon's approach cannot account for dynamics, heterogeneity and cross-sectional dependence in the data. Even less so could previous attempts as they were still framed in terms of pooled and fixed effects estimation approaches.

The relevance of the regional component lies in the different industrial composition of regions (states in the case of U.S.). Behind aggregate data lies a very heterogeneous picture of regional labor markets reflecting disparate initial conditions (see also Draghi, 2014). These dissimilar conditions encompass varying sectoral compositions of employment and unemployment across regions with unemployment rates historically persistently higher in some areas than others. ${ }^{5}$

Dissimilar industrial compositions entails different levels of industrial agglomeration, concentration and specialization. Clearly, the reallocation movements of a region with high agglomeration would have a different impact at aggregate level than those of a region with opposite characteristics. The

\footnotetext{
${ }^{5}$ Dao et al. (2014) using state-specific data, estimate the dynamic effects of regional employment and unemployment. They conclude that the long-run effect of a state-specific shock on the state employment level has decreased over time.
} 
concentration levels of a specific industry may vary widely from region to region. If a sector is highly concentrated in a limited number of regions then its fortunes would mostly affect a restricted area of the country, at least initially. At the same time the regional degree of sectoral specialization (how an industrial sector is relatively large within the economy of a specific region) are likely to differ greatly across U.S. states. Allocative shocks would affect regional labor markets differently according to the initial state of the region industrial composition and result in different patterns of inter and intra reallocation. A change in demand composition would affect differently a region highly specialized in declining sectors from one with a high specialization in expanding industries. Flows of workers from declining to expanding sectors could not necessarily take place within the same region. In some regions the scale of job destruction relative to that of job creation may reduce the job-finding rate, increase the unemployment rate, the unemployment duration spells and workers migration to more favorable areas. For instance, vis-a-vis a change in demand composition a region with an initially high specialization in declining sectors could not provide sufficient opportunities for reallocation in a short or medium run. Its workers would have to look for employment in other regions and look for employment in regions with a favorable industrial composition.

The process of intersectoral reallocation is characterized by heterogeneity, common global factors and spillover effects at regional level. Conventional panel estimators (fixed or random effects), which have been the basis of previous research in this field, would result in misleading inferences and inconsistent estimators (Chudik and Pesaran (2015b)). Recent advances in panel data econometrics with heterogenous slopes and a common factor structure (i.e. cross sectional dependence) and in data availability would allow us to take into account with more rigor the issues of heterogeneity, spillovers and common factors and thus testing and measuring the relevance of sectoral shifts with a higher degree of reliability. Since the outstanding literature on regional labor reallocation has not filled this gap, it is the aim of this paper to do so.

The current study revisits the SSH by bringing to bear heterogeneity, common factors and crosssectional dependence. We account for common factors (i.e. aggregate shocks and local spillovers) and investigate the effects of labor reallocation within U.S. states. First, we extend the homogeneous panel data approach, by employing the Driscoll and Kraay's (1998) Pooled and Fixed Effects estimators. Second, in order to obtain consistent estimates in a dynamic panel with substantial heterogeneity across regions, we use the Pesaran and Smith's (1995) Mean Group Estimators (MG). Third, since 
estimators assuming cross-sectional independence across regions could be inefficient, we extend the heterogeneous slopes Mean Group estimation procedure by implementing the Common Correlated Effects (CCE) estimator proposed by Pesaran (2006), as well as the Augmented Mean Group (AMG) estimator by Bond and Eberhardt (2009) and Eberhardt and Teal (2010) that accounts for crosssectional dependence by means of a 'common dynamic process'. Fourth, given the presence of a lagged dependent variable in our specification form, we apply the recently proposed extension of the Common Correlated Effects estimator by Chudik and Pesaran (2015a) that allows for dynamic panels and relaxes the assumption of strict exogeneity.

\section{ECONOMETRIC Model AND Methodology}

Using pooled time-series-cross-section data (with $N=48$ and $T=264$, comprising 12672 observations) on state unemployment and aggregate U.S. employment, we estimate Lilien's reduced form unemployment equation in a dynamic heterogeneous panel data context as follows:

$$
U_{i, t}=\mu_{i}+\phi_{i} U_{i, t-1}+\beta_{i} \sigma_{i, t}+\lambda_{i}^{\prime} z_{i, t}+\pi_{i}^{\prime} \boldsymbol{w}_{t}+u_{i, t}
$$

where $U_{i, t}$ is the unemployment rate for state $i$ at time $t ; \sigma_{i, t}$ is the state measure of employment cross-sectoral dispersion; the vector $z_{i, t}$ represents a vector of state specific control variables; in our specification the state personal income growth, $\Delta \ln \left(P I_{i, t}\right)$ is included. The vector of aggregate factors $\boldsymbol{w}_{t}$ represents common control variables that capture aggregate demand shocks, common to all states, which in our specification includes the federal funds rate growth, $\Delta F R_{t}$, its variability, $H_{t}$, and the government expenditures growth, $\Delta \ln \left(G_{t}\right)$. Finally, $\mu_{i}$ stands for a set of state-specific fixed effects capturing the influence of unobserved state-specific heterogeneity and $u_{i, t}$ is the error term. ${ }^{6}$

We allow for cross correlation of the disturbances, $u_{i, t}$, assuming that they follow a multi-factor error structure:

$$
u_{i, t}=\gamma_{i}^{\prime} f_{t}+\varepsilon_{i, t}
$$

\footnotetext{
${ }^{6}$ The analysis builds on Lilien's reduced form unemployment equation embedded into a dynamic heterogeneous panel in the form of an ARDL(1,0,0,0) model. The ARDL(1,0,0,0) specification is found to be the most appropriate model according to the Schwarz Bayesian criterion $(\mathrm{SBC})$ and starting with a general $\operatorname{ARDL}(1,1,1,1)$ form on a state-by-state basis. We, thus, continue our analysis using the ARDL(1,0,0,0) specification.
} 
where $f_{t}$ is a $m \times 1$ vector of unobserved common factors that capture cross-sectional dependencies across states, and $\gamma_{i}^{\prime}$ are the state specific associated factor loadings. The idiosyncratic errors, $\varepsilon_{i, t}$, are assumed to be independently distributed across $i$ and $t$ with zero mean and constant variance. Following Chudik et al. (2011) and Chudik and Pesaran (2015b), the factor structure can be further decomposed as $f_{t}=f_{t}^{s}+f_{t}^{w}$, with $f_{t}^{s}$ is a vector of a finite number of 'strong' factors, which capture common global shocks to all states, and $f_{t}^{w}$ is a vector of an infinite number of 'weak' factors, which reflect regional spillover effects across subsets of states.

In this heterogeneous dynamic panel data modeling with a common factor approach, the vector of regressors $\boldsymbol{x}_{i, t}=\left(\sigma_{i, t}, \boldsymbol{z}_{i, t}^{\prime}\right)^{\prime}$ is a $(k+1) \times 1$ vector of observed individual-specific regressors on the $i$ th state at time $t$, vector $\boldsymbol{w}_{t}$ is a $n \times 1$ vector of observed common (aggregate) factors with state specific impact (i.e. observed heterogeneity), while $f_{t}$ is a $m \times 1$ vector of unobserved 'strong' and 'weak' common factors (i.e. unobserved heterogeneity due to country characteristics or regional spillover effects). ${ }^{7}$

Following Lilien (1982), the dispersion proxy for each state $i$ at time $t$ is calculated as the weighted standard deviation of the cross-sectoral employment growth rates using a $K$-sectoral decomposition as follows:

$$
\sigma_{i, t}=\left[\sum_{j=1}^{K} \frac{n_{j, i, t}}{N_{i, t}}\left(\Delta \ln n_{j, i, t}-\Delta \ln N_{i, t}\right)^{2}\right]^{1 / 2},
$$

where $n_{j, i, t}$ is employment in sector $j$ for state $i$ at time $t, N_{i, t}=\sum_{j=1}^{K} n_{j, i, t}$ is aggregate employment at time $t$ for state $i, K$ is the number of sectors (with $j=1,2, \ldots, K$ sectors) in the state $i$ and the term $\frac{n_{j, i, t}}{N_{i, t}}$ is the sector $j$ share of total regional employment at time $t$.

From the outset, the SSH has been beset by the problem of 'observational equivalence' (Lilien, 1982; Abraham and Katz, 1986). The positive correlation between unemployment and sectoral dispersion (as measured by using Lilien's proxy) could be an outcome determined by either aggregate shocks, if cyclical responsiveness varies across sectors, or by changes in labor demand composition. Two alternative theories could accommodate the same stylized facts. Because of this problem of 'observation equivalence', we filter out aggregate effects from the dispersion proxy $\left(\sigma_{i, t}\right)$ and decompose it into an

\footnotetext{
${ }^{7}$ For an extensive survey on heterogeneous panel data models with cross-sectional dependence, see Chudik and Pesaran (2015b).
} 
idiosyncratic component and a component measuring the response to aggregate shock. ${ }^{8,9}$ To obtain the 'purged' measure, we have regressed $\sigma_{i, t}$ on the vector of aggregate variables $\tilde{w}_{t}:{ }^{10}$

$$
\sigma_{i, t}=\alpha_{i}+\sum_{j=0}^{q} \varphi_{j} \tilde{w}_{t-j}+\xi_{i, t}
$$

The estimated residual $\widehat{\xi}_{i, t}$ from Equation 3 stands as the 'purged' component of $\sigma_{i, t}$. This 'purged' dispersion index, that measures only the reallocation shocks, is then used in the reduced form unemployment Equation 1.

We have included the federal funds rate growth, $\Delta F R_{t}$, as a proxy for the monetary policy instrument as well as its variability, $H_{t}$. The measure of monetary policy variability has been generated by estimating a GARCH $(1,1)$ model for $\Delta F R_{t}$ and interpreting the estimated conditional variance as a parametric proxy of the monetary uncertainty $\left(H_{t}\right) .{ }^{11}$ The growth of government expenditures, $\Delta \ln \left(G_{t}\right)$, is introduced to capture the effects of fiscal policy (Mills et al., 1995) while the growth rate of state's personal income $\left(\Delta \ln \left(P I_{i, t}\right)\right)$ is used as a potential source of regional demand shocks. ${ }^{12}$

In order to analyze the effect of sectoral shifts using panel regressions for the U.S. states, we need to consider the issues of dynamics, heterogeneity and cross-sectional dependence that emerge from the specification of Equation 1.

\section{A. Homogeneous estimation Approach}

The standard empirical macroeconometric literature employs pooled estimators adopted from the microeconometric literature, such as the least square dummy variable estimator allowing for individual fixed effects. The fixed effects (FE) model allows the intercepts to differ across regions, while all other coefficients are forced to be identical, and can be estimated by OLS using a simple transformation (within estimator). We extend the homogeneous pooled OLS and fixed effects estimators, by using the Driscoll and Kraay's (1998) extension of nonparametric variance-covariance matrix estimation,

\footnotetext{
${ }^{8}$ This a standard procedure well established in the literature. For a full discussion of the issue see Gallipoli and Pelloni (2008; 2013).

${ }^{9}$ Note that aggregate factors are also taken into account in the panel econometric specification and as a result any evidence in favor of labor reallocation can be considered as relatively "conservative".

${ }^{10}$ The choice of variables included in $\tilde{w}_{t}$ varies across articles. Here, the vector of aggregate variables $\tilde{w}_{t}$ is exactly the same as the vector $w_{t}$. For a full discussion of this issue see Gallipoli and Pelloni (2008; 2013).

${ }^{11}$ Caporale et al. (1996) follow a similar approach to measure inflation uncertainty.

${ }^{12}$ We also implement the analysis using the 3-Month T-Bill interest rate growth, $\Delta T B_{t}$, as the instrument for monetary policy and the government expenditures disaggregated in two parts, the federal government expenditure, $\Delta \ln \left(F G_{t}\right)$, and the local/state government expenditures, $\Delta \ln \left(S G_{t}\right)$, as the fiscal policy instruments for robustness purposes.
} 
which produces heteroskedasticity and autocorrelation consistent standard errors that are robust to the presence of general forms of spatial and cross-sectional dependence. The presence of a lagged dependent variable among the regressors $\left(U_{i, t-1}\right)$ results in a biased OLS fixed effects estimator when $T$ is fixed (Nickell, 1981). Therefore, several suggestions were proposed in the literature. Kiviet (1995) proposes a bias corrected fixed effects estimator, while Arellano and Bond (1991) recommend a Generalized Method of Moments (GMM) estimation procedure. Specifically, the difference GMM estimator (AB-GMM) of Arellano and Bond (1991) first transforms the model using first differences to eliminate the individual effects and then uses the GMM framework of Hansen (1982). Following the work of Arellano and Bover (1995), Blundell and Bond (1998) put forward an extended system estimator that applies additional moment conditions, the system GMM estimator (BB-GMM), which we implement as a complement to the dynamic fixed effects estimation.

\section{B. Heterogeneous Estimation Approach}

The previous standard pooled estimators assume slopes homogeneity across regions. These estimators yield inconsistent estimates in the case of a dynamic panel data model when the slope coefficients differ across regions (Pesaran and Smith, 1995). Given the differences in labor market across the U.S. states, the homogeneity assumption is quite restrictive, and therefore the usage of pooled estimation methods may lead to a substantially heterogeneity bias in the estimated parameters of Lilien's panel version of Equation 1.

One way to obtain consistent estimates in dynamic panels with considerable heterogeneity across regions is to use estimators that allow for slope heterogeneity across states. Pesaran and Smith (1995) propose the Mean Group Estimators (MG) that consists of estimating separate OLS regressions for each region and then calculating averages of the specific coefficients over groups. Furthermore, Pesaran et al. (1999) suggest an intermediate estimator that imposes long-run slope homogeneity between regions but allows for short-run parameters heterogeneity. The pooled mean group (PMG) estimator involves both pooling and averaging of the individual regression coefficients in order to obtain more efficient estimates than the MG estimators under the assumption of slope homogeneity.

Another crucial issue, that is relevant for the regional panel sectoral shifts analysis of unemployment, is the issue of cross-sectional dependence among states. Interdependence between cross-sections is an important characteristic in the analysis of macro and regional panel data models, and estimators based on the assumption of cross-sectional independence may prove inefficient or even inconsistent 
(Sarafidis and Wansbeek, 2012). Therefore, we extend the heterogeneous slopes estimation procedure by implementing the Pesaran (2006) Common Correlated Effects (CCE) estimators that account for the presence of unobserved common factors by using cross-section averages of the dependent and independent variables as additional regressors. Specifically, we consider the Mean Group CCE (CCEMG) extension of the estimator proposed in Pesaran and Smith (1995) as it is more appropriate for our heterogeneous panel data setting. In addition to the CCE approach, we implement the Augmented Mean Group (AMG) estimator proposed by Bond and Eberhardt (2009) and Eberhardt and Teal (2010) that accounts for cross-sectional dependence by means of a 'common dynamic process' in the regional regressions. The 'common dynamic process' is extracted using year dummy coefficients of a pooled regression in first differences and represents the levels-equivalent mean evolution of unobserved common factors across all regions (Eberhardt and Teal, 2010). ${ }^{13}$ Finally, given the presence of a lagged dependent variable in our specification and the need to take into account simultaneously the issues of dynamics, heterogeneity and cross-sectional dependence, we implement the recent extension of the Pesaran (2006) Mean Group Common Correlated Effects estimator proposed in Chudik and Pesaran (2015a) that permits the inclusion of lagged values of the dependent variable and/or weakly exogenous regressors in the panel data model.

Chudik and Pesaran (2015a) allows the estimation of heterogeneous panel data models with a lagged dependent variable. They show that the dynamic CCEMG (dynCCEMG) extension of the CCE estimator performs well and is asymptotically valid when (i) there is a sufficient number of lags of cross-section averages included in the individual equations of the panel alongside with the cross-section averages, and (ii) the number of cross-section averages is at least as large as the number of unobserved common factors.

In order to apply the dynCCEMG estimator we augment Equation 1 with cross-section averages of the dependent and independent variables as well as their lags as additional regressors:

$$
U_{i, t}=\mu_{i}+\phi_{i} U_{i, t-1}+\beta_{i} \sigma_{i, t}+\lambda_{i}^{\prime} z_{i, t}+\pi_{i}^{\prime} \boldsymbol{w}_{\boldsymbol{t}}+\sum_{l=0}^{p_{T}} \delta_{i l}^{\prime} \overline{\boldsymbol{v}}_{\boldsymbol{t}-l}+\varepsilon_{i, t}
$$

where $\bar{v}_{t}=N^{-1} \sum_{i=1}^{N} \mathbf{v}_{i, t}=\left(\bar{U}_{t}, \bar{\sigma}_{t}, \bar{z}_{t}\right)^{\prime}$. We perform the estimation using a different number of lags

\footnotetext{
${ }^{13}$ Bond and Eberhardt (2009) provide evidence that both the CCEMG estimators and the AMG approach perform very well and with similar results in Monte Carlo studies.
} 
of cross-section averages up to the $p_{T}$, where $p_{T}$ is equal to the integer part of $T^{1 / 3}$ as suggested by Chudik and Pesaran (2015a). ${ }^{14}$ Pesaran and Tosetti (2011) shows that the CCE type estimators provide consistent estimates of the slope coefficients (and their SEs) under general cases of cross-sectional dependencies. The latter can arise from spatial spillovers or can be due to the presence of unobserved common factors.

Prior to estimation, we examine the panel data properties of the series. Notably, we investigate i) the order of integration of the series using panel unit root tests, ii) the assumption of crosssectional independence among states using cross-sectional dependence tests, and iii) the issue of slopes heterogeneity across states using poolability tests. Detailed description of the tests is presented in the Appendix.

Following this, we proceed to the main stage of the analysis by estimating the Lilien's dynamic reduced form unemployment relationship for the U.S. states panel, taking into account the issues of dynamics, heterogeneity and common (aggregate) factors through the induction of cross-sectional dependence, by considering alternative estimation procedures for homogeneous and heterogeneous panel data.

\section{Data AND Preliminary Analysis}

\section{A. DATA}

The empirical analysis has been carried out using monthly data over the period 1990:M1-2011:M12 for the 48 contiguous U.S. states (12672 observations overall). ${ }^{15}$ Table 1 presents the abbreviations of the U.S. states used in our analysis. The employment and unemployment per state series were obtained from the U.S. Bureau of Labor Statistics (BLS).

The sectoral shifts proxy is computed per state by using the employment shares of the available sectoral decomposition of monthly non-agricultural employment consisting of the following sectors: I) Goods providing: (1) Mining - Logging - Construction, (2) Manufacturing (with a further disaggregation on (2.1) Durable and (2.2) Non-Durable goods), (3) Trade - Transportations (with a further disaggregation on (3.1) Wholesale trade, (3.2) Retail trade and (3.3) Transportations), II) Services

\footnotetext{
${ }^{14}$ Chudik and Pesaran (2015a) have also proposed time series bias corrected versions of the Mean Group dynamic CCE (dynCCEMG) estimator. Since our interest is on the coefficient of $\sigma_{i, t}$ and not on the parameter of the lagged depended variable $\left(U_{i, t-1}\right)$, and following the suggestion of Chudik and Pesaran (2015a) that the uncorrected dynCCEMG estimator is preferred, we thus present results without the bias corrected version of the dynCCEMG estimator.

${ }^{15}$ We exclude from our analysis the non-adjoining states of Alaska and Hawaii.
} 
providing: (4) Information, (5) Financial activities, (6) Professional activities, (7) Education - Health, (8) Leisure - Hospitality, (9) Other services and (10) Government sector for the U.S. states. ${ }^{16}$ Using this 10-industry decomposition, we compute our benchmark measure $\sigma_{i, t}^{9}$ using information on the 9 "super-sectors" of the economy (excluding the government sector) while we also build the $\sigma_{i, t}^{13}$, a 13-sectors decomposition measure of labor reallocation by using all the available disaggregation in our dataset (including the government sector). Finally, for robustness purposes and by following the work of Pelloni and Polasek (2003) and Panagiotidis and Pelloni (2007), the measure of sectoral shifts is computed using the employment shares of the construction, finance, manufacturing, and trade sectors for the 48 U.S. states $\left(\sigma_{i, t}^{4}\right) .{ }^{17}$ Panel (A) of Table 2 presents pooled descriptive statistics for the sectoral employment data.

For the purposes of our econometric analysis, we use the logarithmic form of the unemployment rate, $U_{i, t}^{\text {Logarithmic }}=\ln \left(u_{i, t}\right)$, as well as the logistic transformation, $U_{i, t}^{\text {Logistic }}=\ln \left(\frac{u_{i, t}}{1-u_{i, t}}\right)$, where $u_{i, t}$ is the unemployment rate, following the suggestion by Wallis (1987) to employ the logistic transformation of the unemployment rate, a variable bounded between 0 and 1 (see also Panagiotidis and Pelloni, 2007). ${ }^{18}$

The aggregate series on the monetary variables, $F R_{t}$ and $T B_{t}$, as well as the fiscal variables, $G_{t}$, $F G_{t}$ and $S G_{t}$, are taken from the Federal Reserve Economic Data (FRED) database and transformed into first-differences $\left(\Delta F R_{t}\right.$ and $\left.\Delta T B_{t}\right)$ and logarithmic first-differences $\left(\Delta \ln \left(G_{t}\right), \Delta \ln \left(F G_{t}\right)\right.$ and $\left.\Delta \ln \left(S G_{t}\right)\right){ }^{19}$ The conditional variance $\left(H_{t}\right)$ of a GARCH $(1,1)$ model for $\Delta F R_{t}$ proxies monetary variability. Finally, the state personal income, $P I_{i, t}$, transformed into logarithmic first-differences is obtained from the U.S. Bureau of Economic Analysis (BEA). Panel (B) of Table 2 presents pooled descriptive statistics for the unemployment series, the sectoral shifts measures and the aggregate monetary variables used in our regression analysis.

\section{B. Preliminary Data Analysis}

Our preliminary analysis starts with the Lilien's proxy (dispersion per state). Figures 1 and 2 present the unemployment rate and Lilien's proxy graphs at the national and regional U.S. level, respectively. Figure 1 shows the aggregate unemployment rate and the alternative measures of the dispersion index

\footnotetext{
${ }^{16}$ All sectoral series were seasonally adjusted using Eviews Census X12 program.

${ }^{17}$ In a similar manner, we compute also two intermediate decomposition measures, the $\sigma_{i, t}^{10}$ and $\sigma_{i, t}^{7}$ for completeness of the analysis.

${ }^{18}$ Cavaliere and Xu (2014) stress the issue of stationarity properties of variables in the presence of bounds.

${ }^{19}$ All fiscal variables were published in quarterly frequency and have been transformed into monthly using a lineal interpolation method.
} 
for U.S. We can observe that both dispersion indexes $\left(\sigma_{i, t}^{9}\right.$ and $\left.\sigma_{i, t}^{13}\right)$ have similar patterns, and that both are rising sharply during recessions (early 1990s, 2001 and the Great Recession of 2007-2009) as measured by the National Bureau of Economic Research (NBER). Furthermore, the two dispersion indexes, the unpurged Lilien's measure as well as it's 'purged' counterpart, display a similar behavior.

Figure 2 present the state-by-state graphs of the unemployment rate and the dispersion indexes. The graphs per state reveal similar patterns to the aggregate behavior. However, the presence of substantial heterogeneity is obvious for both the unemployment rate and the dispersion index across states. Thus it is essential to take into account this heterogeneity (alongside any potential interdependence across U.S. states) in our panel data analysis.

Table 3 presents the values of Lilien's index $\left(\sigma_{i, t}^{9}\right)$ in 1990, 2000 and 2011. Looking first at the averages, among the four largest U.S. states (population wise) (CA, TX, NY and FL), FL has the highest average over the two decade period (0.0039), which implies more reallocation, followed by CA, NY and TX. A more clear picture is emerging from Table 4 that presents the regional employment structure per U.S. state. Comparing 1990 with 2011, one of the most important characteristics emerging from these two decades was the decline of traditional sectors such as manufacturing. Focusing again on the four largest states, we can observe that in 1990, manufacturing did represent $15.70 \%$ of employment in CA, $13.30 \%$ in TX, 12\% in NY and 9.46\% in FL. Twenty one years later the percentages are: $8.9 \%$ (CA), 7.9\% (TX), 5.3\% (NY), 4.28\% (FL). This momentous decline was accompanied by an increase in new, more dynamic sectors on the services side of the economy.

\section{EMPIRICAL RESULTS}

We begin our analysis by conducting formal tests to examine the properties of poolability, crosssectional dependence and stationarity (unit roots) for our panel data set. Specifically, we conduct univariate and panel unit root tests to determine the level of integration of our series. We perform the $\mathrm{ADF}$ unit root tests for the variables that are common to all states, $F R_{t}, H_{t}, T B_{t}, \ln \left(G_{t}\right), \ln \left(F G_{t}\right)$ and $\ln \left(S G_{t}\right)$. Additionally, we employ one first generation (the IPS test of Im et al. (2003)) and one second generation (the CIPS test of Pesaran (2007) that accounts for cross-sectional dependence) panel unit root tests for our panel variables $\left(U_{i, t}, \sigma_{i, t}\right.$ and $\left.\ln \left(P I_{i, t}\right)\right)$. Table 5 presents the ADF unit root tests. They reveal that all variables are $I(1)$ except $H_{t}$ which is $I(0)$. The panel results, reported in Table 6, bear out that both tests clearly indicates that the unemployment series and the sectoral 
shifts index are stationary variables, while state personal income is found to be $I(1)$. Within a time series perspective, Abadir et al. (2013) also claim that unemployment series are not of the integrated type.

The issue of cross-sectional dependence is examined by applying the $C D_{P}$ and $C D_{L M}$ versions of the CSD test (Table 7). The null hypothesis of no cross-sectional correlation among the U.S. states panel is rejected at the $5 \%$ level of significance, indicating that the hypothesis of cross-sectional independence in our dataset is clearly violated and thus we need to account for cross-sectional dependence across the U.S. states.

Furthermore, the assumption of common slope parameters in our states panel estimation is tested by an F-test (Chow test) and the Pesaran and Yamagata's (2008) standardized version of Swamy's test (Delta test). From Table 8, the poolability tests reject the hypothesis of common slopes. It indicates substantial heterogeneity among U.S. states.

Before we proceed with the panel estimates, we report the results for the Lilien's dynamic reduced form unemployment relationship at the aggregate level in the U.S. over the period 1990:M1-2011:M12 (Table 9). Clearly, in all different specifications of the estimated equation, using alternative transformation of the unemployment series (logistic and logarithmic transformation), alternative disaggregation levels $\left(\sigma_{t}^{9}\right.$ and $\sigma_{t}^{13}$ ) and different methods of estimation (OLS and GMM), we can observe a positive and significant relationship between unemployment rate and the measures of dispersion. These results support the view of Mills et al. (1995) and extend their time series evidence to the recent period (1990-2011). The time series approach for the aggregate specification (Table 9) reflects Lilien's initial specification that cannot discriminate between aggregate and sectoral shocks. Furthermore it does not take into account the regional dimension and the mobility between states (note also the increase in the number of observations from 263 in the time series case to 12624 in the panel data case). Such time series modelling suffers from potential aggregation bias and employs a relatively limited dataset.

Hence we proceed by estimating a panel version of Lilien's dynamic reduced form unemployment relationship for the U.S. states, and take into account the issues of dynamics, heterogeneity and common factors. In addition, for robustness, we also employ alternative estimation approaches for both homogeneous and heterogeneous panel data. Analogously to the classification of Eberhardt et al. (2013), Table 10 presents an overview of the adopted estimators and classifies them according to the assumptions made over cross-sectional dependence and parameter heterogeneity. 
Having established a significant positive evidence on the aggregate level, we examine the regional dimension of the sectoral reallocation for the 48 U.S. states using panel estimates of the dynamic reduced form Equation 1 as an $\operatorname{ARDL}(1,0,0,0)$ specification (see footnote 3). ${ }^{20}$ Table 11 presents the initial (homogeneous) panel estimates of the effects of Lilien's sigma index on the unemployment rate in the U.S. states. In all alternative specifications - the Driscoll and Kraay's (1998) POLS and Fixed Effects estimators, robust to cross-sectional dependence, and the dynamic GMM approach, robust to endogeneity issues of explanatory variables - we observe a significant but almost negligible negative effect of the measure of monetary policy shock $\left(\Delta F R_{t}\right)$ on unemployment and a small positive impact of monetary policy variability $\left(H_{t}\right)$. The impact of the fiscal policy $\left(\Delta \ln \left(G_{t}\right)\right)$ is found to be positive and significant. Finally, the effect of state specific personal income $\left(\Delta \ln \left(P I_{i, t}\right)\right)$ is negative and highly significant in all specifications. All alternative estimation methods yield a positive and significant effect of the dispersion index on unemployment, with an impact ranging from 0.61 (in the case of the logarithmic transformation using the POLS estimator) to 0.82 (in the version of logistic transformation with the Fixed Effects model). The evidence from the homogeneous panel estimates strongly corroborates previous results of a significant effect of allocative shocks (see among others, De Serres et al. (2002); Estevão and Tsounta (2011); Simon (2014)).

So far we have established that purged sigma as a measure of labor reallocation is positive and statistically significant at the aggregate level for the U.S. (Table 9). The same holds as we move from the time series dimension $(T=264)$ to the homogeneous panel (POLS, Fixed Effects and GMM) estimation ( $T=264$ and $N=48$ ) in Table 11. However, these homogeneous parameter methodologies, used by all previous studies, do not take into account aggregate factors and state spillover effects which is macroeconomically important in this framework. As a result we proceed with Table 12 that presents the heterogeneous panel estimates of the same specification. In particular we present the MG, AMG, and alternative forms of the CCE mean group estimators such as the CCEMG, the dynCCEMG and the neighbour weighted CCEMG $\left(\mathrm{CCEMG}^{W}\right)$ estimators.

Table 12 presents the estimates that were described in Section 3.2, i.e. estimates that take into account heterogeneity (MG) as well as both heterogeneity and cross-sectional dependence (AMG, CCEMG and dynCCEMG). The results from Table 12 highlight the statistical significance of the lagged

\footnotetext{
${ }^{20}$ In order to produce results that clearly distinguish the aggregate effects from the dispersion proxy, we proceed to estimate the dynamic reduced form Equation 1 using the 'purged' dispersion index in our analysis (Abraham and Katz, 1986). The results using the unpurged sigma index are qualitatively similar. These results are available upon request.
} 
value of unemployment. This persistence is well documented in the literature. With regard to the coefficient of sigma, we observe that the 'purged' dispersion index is affecting unemployment rate in a positive and statistically significant way in all alternative estimation techniques for both the logistic and the logarithmic transformation of unemployment. The sigma $\left(\sigma_{i, t}\right)$ coefficient ranges from 0.41 (0.38) in the logistic transformation (logarithmic transformation) using the heterogeneous common correlated effects mean group (CCEMG) estimator of Pesaran (2006) that accounts for cross-sectional dependence to $0.88(0.81)$ in the mean group (MG) estimator of Pesaran and Smith (1995) that allows for slope heterogeneity but assumes cross-sectional independence. The MG (heterogeneous) coefficient of 0.877 (column 1 in Table 12) is of similar magnitude with the DK-FE (homogeneous) coefficient of 0.819 (column 2 in Table 11) but is reduced (almost by half) to the 0.433 under dynCCEMG that accounds for both heterogeneity and cross-sectional dependence. The latter highlights that when the cross state dependence is taken into account, the effects of labor reallocation is halved. Moreover, once we consider the heterogeneous estimates that account for cross-sectional dependence through the Common Correlated Effects approach (CCEMG and dynCCEMG), the impact of sigma on unemployment is about half of that emerging from the homogeneous estimates in Table 11 . This positive and significant effect of purged sigma is a noteworthy result since it corroborates the labor reallocation hypothesis when one takes into account aggregate factors in the econometric specification via the cross-section dependence.

The coefficient of the growth rate of the state's personal income $\left(\Delta \ln \left(P I_{i, t}\right)\right)$ is negative and significant under all specifications. This variable is state specific and the estimates reflect the inverse relationship between unemployment and the growth rate of income (an estimate of the Okun's coefficient in a sense). The monetary policy growth rate $\left(\Delta F R_{t}\right)$ is significant with a negative sign in the homogeneous parameter estimates and for the MG and AMG. Once we properly account for common factors through the Pesaran's CCE approach in the specification (CCEMG and dynCCEMG) its significance evaporates. The monetary policy variability $\left(H_{t}\right)$ displays a similar behavior: it is positive and significant under cross-sectional independence while it becomes insignificant when we allow for cross-sectional dependence. Finally, $\Delta \ln \left(G_{t}\right)$ has a coefficient which is positive and significant both in the homogeneous parameter estimates (Table 11) and in the heterogeneous parameter estimates if cross-sectional dependence is ignored (MG in Table 12). Under the CCEMG and dynCCEMG approaches, its significance disappears. The root mean squared error (RMSE) statistic is provided in 
both the homogeneous and in the heterogeneous case (Table 11 and 12). We observe a reduction

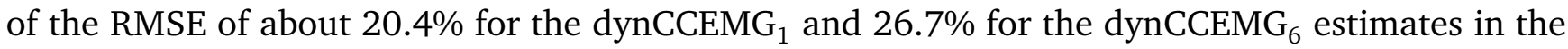
logistic specification and $24.7 \%$ for the dynCCEMG ${ }_{1}$ and $30.6 \%$ for the dynCCEMG 6 estimates in the logarithmic specification compared to the homogeneous estimates (DK FE). This decrease in the measure of goodness of fit indicates the importance of cross-sectional dependence and parameter heterogeneity in the U.S. states panel analysis. The preferred model for both the logistic and the logarithmic transformation of unemployment is the Chudik and Pesaran's dynCCEMG 6 (with the addition of six lags of cross-section averages) estimator that accounts for dynamics in the specification where labor reallocation and state income are the only variables that enter in a statistically significant fashion (positive the former and negative the latter). ${ }^{21}$

The CCE type estimators (CCEMG and dynCCEMG) account for the presence of unobserved common factors with state specific impact, such as 'strong' factors which reflects aggregate shocks that affect all states and 'weak' factors which reflects regional spillovers that affects only subsets of states. The augmentation of the panel regression equations with the cross-section averages of the dependent and independent variables, as formulated by the standard CCE approach, is based on an equal weighting scheme of the cross-section averages for all states. In order to test whether the cross-sectional spillover effects are stronger among states which share borders, and thus, have an impact on the estimated coefficient of sigma, we follow the approach of Eberhardt and Teal (2013), and impose a weighting scheme for the construction of the cross-section averages based on the spatial neighborhood information among the U.S. states. ${ }^{22}$ Thus, using this 'border/neighborhood impact' weighted CCE approach, we can test the hypothesis that state $i$ is affected mainly by 'weak' unobserved common factors which are similar in states that share borders (i.e. spatial spillovers), but is less affected by the set of the common 'strong' factors which influence states without border neighborhoods. Table 12 (columns 7-9 and 16-18) present the estimations based on the 'neighbour' weighted CCEMG estimator. The results show that the 'neighbour' weighted CCE approach provides similar estimated coefficients of sigma with the estimates without the neighborhood weighted scheme, and confirms that the CCE approach of Pesaran (2006) is effective to deal with more general cases

\footnotetext{
${ }^{21}$ The vector of aggregate common control variables $\boldsymbol{w}_{t}$ (which here includes $\Delta F R_{t}, H_{t}$ and $\Delta \ln \left(G_{t}\right)$ ) that capture aggregate demand shocks can be viewed in the heterogeneous dynamic panel data modeling with a common factor approach (CCEMG and dynCCEMG) as a vector of 'observed' common factors with state specific impact. Thus, the inclusion of these variables in the CCEMG and dynCCEMG models tend to approximate the unobservable common factors, $f_{t}$, in addition to the cross-sectional averages of the dependent and independent variables (see Pesaran et al., 2013 and Chudik and Pesaran, 2015b).

${ }^{22}$ We would like to thank an anonymous referee for drawing our attention to this point.
} 
of error cross-section dependencies such as spatial error spillover effects, see Pesaran and Tosetti $(2011) .^{23}$

Independently from the different set-up assumptions, all the alternative empirical estimators, bear out a positive and significant effect of the dispersion index on unemployment. However, we can observe that in the preferred model $\left(\right.$ dynCCEMG $\left._{6}\right)$, which accounts for both heterogeneity and crosssectional dependence, the coefficient of sigma is half what is under the Fixed Effects (homogeneous case) as well as under the Mean Group (heterogeneous case) estimators.

\section{A. Robustness Check}

Given the conclusion from the previous section where labor reallocation was found to have a positive and significant effect on unemployment, we assess the robustness of our results. Table 13 presents the results for the dynCCEMG estimator under alternative specifications (dynCCEMG ${ }_{1}$ ). The first column repeats the column 5 from Table 12 (coefficient 0.433). In the second specification, we replace purged sigma with the unpurged reallocation index. In columns 3, 5, 6 and 8, we consider alternative purging mechanisms and a more disaggregated sigma $\left(\sigma_{i, t}^{13}\right)$. In column 4 , we examine the impact of state's personal income on the results. In column 5 , we have replaced $\Delta F R_{t}$ with the growth rate of the Treasury Bill $\left(\Delta T B_{t}\right)$ and its GARCH volatility $\left(H_{t}^{T B}\right)$. Finally, column 7 replaces $\Delta \ln \left(G_{t}\right)$ with fiscal policy dissagregated in federal government, $\Delta \ln \left(F G_{t}\right)$, and state government, $\Delta \ln \left(S G_{t}\right)$. The overall conclusion is that the effect of labor reallocation on unemployment remains positive and significant in all cases, so further strengthening the above results (average coefficient 0.43).

How could the first generation 'homogeneous' estimates compare with those taking into account the dynamics, heterogeneity and cross-sectional dependence? Looking at Tables 11 and 12, we can compare the dispersion index effect on unemployment both under POLS and FE (first generation estimates) with the 'heterogeneous' dynCCEMG estimator that accounts for dynamics in the specification. The former overestimates the impact of reallocation ( 0.66 and 0.82 compared with 0.43 and 0.49 when accounting for both heterogeneity and cross-sectional dependence). This upward bias stems from ignoring cross-sectional dependence in the estimates. The heterogeneity bias is negligible due to the relatively large time dimension of our data set $(T=264$ and $T>N) \cdot{ }^{24,25}$ Our results, using

\footnotetext{
${ }^{23}$ According to Pesaran and Tosetti (2011), the attraction of the CCE approach is that it does not require a quantification of the exact relative position of the units in space, which is required by the spatial type estimators.

${ }^{24}$ The Mean Group 'heterogeneous' estimation results are found to be qualitatively but also quantitatively very similar with those of the Fixed Effects 'homogeneous' estimates.

${ }^{25}$ Sarafidis and Wansbeek (2012) present evidence that estimators neglecting cross-sectional dependence across errors are inefficient
} 
a 'purged' Lilien's (1982) dispersion proxy, are considerably higher than those reported by Simon (2014) based on Neumann and Topel's (1991) dispersion measure.

Finally, when we deal with cross-sectional dependence by means of a 'common dynamic process' using the AMG estimator, we can see that the impact of sigma is higher and more significant than that computed with the common correlated effects approach (CCEMG and dynCCEMG). Instead, it is close to the effect generated by the standard heterogeneous MG estimator. However, the $t$-stat for the coefficient generated under the AMG estimator is at least twice as large. This outcome holds also when we use the logarithmic transformation of unemployment.

Given the cumulated evidence under our approach and taking into account the verification of cross-sectional dependence and parameter heterogeneity in the U.S. states panel, we turn our analysis to the response of the unemployment rate to different levels of disaggregation of the dispersion index using the dynamic common correlated effects mean group (dynCCEMG) estimator of Chudik and Pesaran (2015a). To facilitate comparisons, we implement a homogeneous counterpart, the Driscoll and Kraay's (1998) Fixed Effects estimator. The alternative measures of dispersion affect unemployment both positively and significantly (Table 14). When we focus on the effectiveness of the dispersion index on unemployment, we find that the impact of the dispersion index depends on the level of disaggregation embodied in its construction. The more disaggregated sigma is $\left(\sigma_{i, t}\right)$, the weaker is its impact and the lower is its significance (lower estimate and $t$-stat in the case of 13 sectors, see Table 14). This is of interest since these alternative indexes appear to be qualitatively similar (see the summary statistics of the dispersion indexes in Table 2). This result supports Parker's (1992) argument suggesting that it is mobility across the 4 major sectors that matters $\left(\sigma_{i, t}^{4}\right.$ index, includes construction, finance, manufacturing, and trade sectors).

Summing up, our results highlight the positive (though not as large as initially though under simpler assumptions) and significant impact of the dispersion index on unemployment and bear out the evidence of Lilien (1982). This corroboration emerges in the dual sectoral and geographical dimension of our panel data approach which accounts for dynamics, heterogeneity and common (aggregate) factors via cross-sectional dependence. The evidence that emerges conforms with the recent empirical literature (see Estevão and Tsounta (2011); Simon (2014)). Our estimators that take into account the above mentioned characteristics, provide moderate but significant coefficients. Our 
analysis reveals the significance of labor reallocation (sectoral shocks) for unemployment even when unobserved common factors (aggregate shocks) are taken into account.

\section{CONCLUSIONS}

Draghi (2014) points that behind aggregate data lies a very heterogeneous picture. Our exercise walks in a similar path with the aim to reveal the extend at which the regional dimension in the labor reallocation process is affecting the macroeconomic behavior of unemployment. We study the unemployment effects of labor reallocation within U.S. states and extend previous analysis in this field in two dimensions. First, we use a large monthly dataset spanning more than two decades for 48 U.S. states (12672 observations). Thus we can overcome the limited data sets constraint of several past aggregate time series approaches. Second, for the first time in the analysis of the unemployment effects of labor reallocation, we introduce recent panel data estimation techniques that can account for the dynamics, parameter heterogeneity, aggregate factors and cross-sectional dependence. These issues are inherent and crucial to the macroeconomic problem and have not been addressed previously.

Labor reallocation has been captured by a 'purged' Lilien's dispersion index which was calculated for different levels of disaggregation to examine the sensitivity of the outcome. Empirical evidence bears out the presence of cross-sectional dependence as well as the heterogeneity among states and as a result they should be taken into account explicitly. The findings provide strong support for a positive and significant effect of the alternative measures of dispersion on unemployment. The impact of labor dispersion index on unemployment is half the size (although still positive and significant) when heterogeneity and cross state dependence is taken into account. This outcome is robust under alternative specifications and assumptions. 


\section{AbBreviations}

ADF : $\quad$ Augmented Dickey-Fuller

AMG : $\quad$ Augmented Mean Group

ARDL : $\quad$ Autoregressive Distributed Lag

BEA : $\quad$ Bureau of Economic Analysis

BLS : $\quad$ Bureau of Labor Statistics

CADF : $\quad$ Cross-Sectionally Augmented ADF

CIPS : $\quad$ Cross-Sectionally Augmented IPS

CCE : $\quad$ Common Correlated Effects

CCEMG : Common Correlated Effects Mean Group

CSD : $\quad$ Cross-Sectional Dependence

dynCCEMG : Dynamic Common Correlated Effects Mean Group

FE : $\quad$ Fixed Effects

FRED : $\quad$ Federal Reserve Economic Data

GARCH : Generalized AutoRegressive Conditional Heteroskedasticity

GMM : $\quad$ Generalized Method of Moments

IPS : $\quad$ Im, Pesaran and Shin

LM : $\quad$ Lagrange Multiplier

MG : $\quad$ Mean Group

NBER : $\quad$ National Bureau of Economic Research

OLS : $\quad$ Ordinary Least Squares

POLS : $\quad$ Pooled Ordinary Least Squares

PMG : $\quad$ Pooled Mean Group

RH : $\quad$ Reallocation Hypothesis

RMSE : $\quad$ Root Mean Squared Error

RSS : $\quad$ Residual Sum of Squares

SBC : $\quad$ Schwarz Bayesian Criterion 


\section{REFERENCES}

Abadir, K. M., G. Caggiano, and G. Talmain. "Nelson-Plosser Revisited: The ACF Approach." Journal of Econometrics, 175(1), 2013, 22-34.

Abowd, J. M., P. Corbel, and F. Kramarz. "The Entry And Exit Of Workers And The Growth Of Employment: An Analysis Of French Establishments." The Review of Economics and Statistics, 81(2), 1999, 170-187.

Abraham, K. G. and L. F. Katz. "Cyclical Unemployment: Sectoral Shifts or Aggregate Disturbances?" Journal of Political Economy, 94, 1986, 507-522.

Aghion, P. and P. Howitt. "A Model of Growth through Creative Destruction." Econometrica, 60(2), 1992, 323-351.

Arellano, M. and S. Bond. "Some Tests of Specification for Panel Data: Monte Carlo Evidence and an Application to Employment Equations." Review of Economic Studies, 58(2), 1991, 277-97.

Arellano, M. and O. Bover. "Another Look at the Instrumental Variable Estimation of Error-Components Models." Journal of Econometrics, 68(1), 1995, 29-51.

Baltagi, B. Econometric Analysis of Panel Data. Chichester, UK: John Wiley \& Sons, 2008.

Baltagi, B. H., G. Bresson, and A. Pirotte. "Panel Unit Root Tests and Spatial Dependence." Journal of Applied Econometrics, 22(2), 2007, 339-360.

Banerjee, A., M. Marcellino, and C. Osbat. "Some Cautions on the Use of Panel Methods for Integrated Series of Macroeconomic Data." Econometrics Journal, 7(2), 2004, 322-340.

Blanchard, O. J. and L. F. Katz. "Regional Evolutions." Brookings Papers on Economic Activity, 23(1), 1992, 1-76.

Blundell, R. and S. Bond. "Initial Conditions and Moment Restrictions in Dynamic Panel Data Models." Journal of Econometrics, 87(1), 1998, 115-143.

Bond, S. and M. Eberhardt. "Cross-Section Dependence in Nonstationary Panel Models: a Novel Estimator." MPRA Paper 17692, University Library of Munich, Germany, 2009.

Breusch, T. S. and A. R. Pagan. "The Lagrange Multiplier Test and Its Applications to Model Specification in Econometrics." Review of Economic Studies, 47(1), 1980, 239-53.

Burgess, S., J. Lane, and D. Stevens. "Job Flows, Worker Flows, and Churning." Journal of Labor Economics, 18(3), 2000, 473-502. 
Caporale, T., K. Doroodian, and M. R. M. Abeyratne. "Cyclical Unemployment: Sectoral Shifts or Aggregate Disturbances? A Vector Autoregression Approach.” Applied Economics Letters, 3(2), 1996, 127-130.

Cavaliere, G. and F. Xu. "Testing for Unit Roots in Bounded Time Series." Journal of Econometrics, 178(P2), 2014, 259-272.

Chen, J., B. Trehan, P. Kannan, and P. Loungani. "New Evidence on Cyclical and Structural Sources of Unemployment.” IMF Working Papers 11/106, International Monetary Fund, 2011.

Chow, G. C. "Tests of Equality Between Sets of Coefficients in Two Linear Regressions." Econometrica, 28(3), 1960, 591-605.

Chudik, A. and M. H. Pesaran. "Common Correlated Effects Estimation of Heterogenous Dynamic Panel Data Models with Weakly Exogenous Regressors.” Journal of Econometrics, 188(2), 2015a, $393-420$.

—. "Large Panel Data Models with Cross-Sectional Dependence: A Survey." In The Oxford Handbook on Panel Data, edited by B. H. Baltagi. Oxford: Oxford University Press, 2015 b.

Chudik, A., M. H. Pesaran, and E. Tosetti. "Weak and strong cross-section dependence and estimation of large panels." Econometrics Journal, 14(1), 2011, C45-C90.

Dao, M., D. Furceri, and P. Loungani. "Regional Labor Market Adjustments in the United States." IMF Working Papers 14/211, International Monetary Fund, 2014.

Davis, S. J. "Fluctuations in the Pace of Labor Reallocation." Carnegie-Rochester Conference Series on Public Policy, 27(1), 1987, 335-402.

Davis, S. J., R. J. Faberman, and J. Haltiwanger. "The Flow Approach to Labor Markets: New Data Sources and Micro-Macro Links." Journal of Economic Perspectives, 20(3), 2006, 3-26.

_. "Recruiting Intensity during and after the Great Recession: National and Industry Evidence." The American Economic Review, 102(3), 2012, 584-588.

Davis, S. J. and J. Haltiwanger. "Gross Job Creation, Gross Job Destruction, and Employment Reallocation.” The Quarterly Journal of Economics, 107(3), 1992, 819-863.

De Serres, A., S. Scarpetta, and C. De La Maisonneuve. "Sectoral Shifts in Europe and the United States: How They Affect Aggregate Labour Shares and the Properties of Wage Equations." OECD Economics Department Working Papers 326, OECD Publishing, 2002.

Diamond, P. “Cyclical Unemployment, Structural Unemployment.” IMF Economic Review, 61(3), 2013, 
$410-455$.

Draghi, M. "Unemployment in the Euro Area." Speech by Mario Draghi, President of the ECB, Annual Central Bank Symposium in Jackson Hole, 22 August 2014, 2014.

Driscoll, J. C. and A. C. Kraay. "Consistent Covariance Matrix Estimation With Spatially Dependent Panel Data." The Review of Economics and Statistics, 80(4), 1998, 549-560.

Eberhardt, M., C. Helmers, and H. Strauss. "Do Spillovers Matter When Estimating Private Returns to R\&D?" The Review of Economics and Statistics, 95(2), 2013, 436-448.

Eberhardt, M. and F. Teal. "Productivity Analysis in Global Manufacturing Production.” Economics Series Working Papers 515, University of Oxford, Department of Economics, 2010.

—_. "No Mangoes in the Tundra: Spatial Heterogeneity in Agricultural Productivity Analysis." Oxford Bulletin of Economics and Statistics, 75(6), 2013, 914-939.

Elsby, M. W. L., B. Hobijn, and A. Sahin. "The Labor Market in the Great Recession.” Brookings Papers on Economic Activity, 41(1), 2010, 1-69.

Estevão, M. and E. Tsounta. "Has the Great Recession Raised U.S. Structural Unemployment?" IMF Working Papers 11/105, International Monetary Fund, 2011.

Everaert, G. and T. De Groote. "Common Correlated Effects Estimation of Dynamic Panels with Cross-Sectional Dependence." Econometric Reviews, 2014, forthcoming.

Gallipoli, G. and G. Pelloni. "Aggregate Shocks vs Reallocation Shocks: an Appraisal of the Applied Literature.” Working Paper Series 27-08, Rimini Centre for Economic Analysis, 2008.

_. "Macroeconomic Effects of Job Reallocations: A Survey." Review of Economic Analysis, 5(2), 2013, 127-176.

Hamermesh, D. S., W. H. J. Hassink, and J. C. van Ours. "Job Turnover and Labor Turnover: A taxinomy of Employment Dynamics.” Annales d'Economie et de Statistique, (41-42), 1996, 21-40.

Hansen, L. P. "Large Sample Properties of Generalized Method of Moments Estimators." Econometrica, 50(4), 1982, 1029-54.

Im, K. S., M. H. Pesaran, and Y. Shin. "Testing for Unit Roots in Heterogeneous Panels." Journal of Econometrics, 115(1), 2003, 53-74.

Keane, M. P. "Sectoral Shift Theories of Unemployment: Evidence from Panel Data." Institute for empirical macroeconomics discussion paper, no. 28, Federal Reserve Bank of Minneapolis, 1991.

Keane, M. P. and E. S. Prasad. "The Employment and Wage Effects of Oil Price Changes: A Sectoral 
Analysis." The Review of Economics and Statistics, 78(3), 1996, 389-400.

Kiviet, J. F. “On Bias, Inconsistency, and Efficiency of Various Estimators in Dynamic Panel Data Models." Journal of Econometrics, 68(1), 1995, 53-78.

Lilien, D. M. "Sectoral Shifts and Cyclical Unemployment." Journal of Political Economy, 90(4), 1982, 777-793.

Medoff, J. L. "U.S. Labor Markets: Imbalance, Wage Growth, and Productivity in the 1970s." Brookings Papers on Economic Activity, 14, 1983, 87-128.

Mills, T. C., G. Pelloni, and A. Zervoyianni. "Unemployment Fluctuations in the United States: Further Tests of the Sectoral-Shifts Hypothesis." The Review of Economics and Statistics, 77(2), 1995, 294-304.

Neumann, G. and R. Topel. "Employment Risk, Sectoral Shifts and the Geographic Distribution of Unemployment.” Discussion Paper 84-3, Economic Research Center/NORC, 1984.

Neumann, G. R. and R. H. Topel. "Employment Risk, Diversification, and Unemployment." The Quarterly Journal of Economics, 106(4), 1991, 1341-65.

Nickell, S. J. "Biases in Dynamic Models with Fixed Effects." Econometrica, 49(6), 1981, 1417-26.

O'Connell, P. G. J. "The Overvaluation of Purchasing Power Parity.” Journal of International Economics, 44(1), 1998, 1-19.

Panagiotidis, T. and G. Pelloni. "Nonlinearity In The Canadian And U.S. Labor Markets: Univariate And Multivariate Evidence From A Battery Of Tests.” Macroeconomic Dynamics, 11(05), 2007, 613-637. Parker, J. "Structural Unemployment in the United States: The Effects of Interindustry and Interregional Dispersion.” Economic Inquiry, 30(1), 1992, 101-16.

Pelloni, G. and W. Polasek. "Macroeconomic Effects of Sectoral Shocks in Germany, The U.K. and, The U.S. A VAR-GARCH-M Approach." Computational Economics, 21(1), 2003, 65-85.

Pesaran, H. M. and T. Yamagata. "Testing Slope Homogeneity in Large Panels." Journal of Econometrics, 142(1), 2008, 50-93.

Pesaran, M. H. “General Diagnostic Tests for Cross Section Dependence in Panels.” IZA Discussion Papers 1240, Institute for the Study of Labor (IZA), 2004.

—_. "Estimation and Inference in Large Heterogeneous Panels with a Multifactor Error Structure." Econometrica, 74(4), 2006, 967-1012.

—. "A Simple Panel Unit Root Test in the Presence of Cross-Section Dependence." Journal of 
Applied Econometrics, 22(2), 2007, 265-312.

Pesaran, M. H., Y. Shin, and R. P. Smith. "Pooled Mean Group Estimation of Dynamic Heterogeneous Panels." Journal of the American Statistical Association, 94(446), 1999, 621-634.

Pesaran, M. H., L. V. Smith, and T. Yamagata. "Panel Unit Root Tests in the Presence of a Multifactor Error Structure." Journal of Econometrics, 175(2), 2013, 94-115.

Pesaran, M. H. and R. Smith. "Estimating Long-Run Relationships from Dynamic Heterogeneous Panels." Journal of Econometrics, 68(1), 1995, 79-113.

Pesaran, M. H. and E. Tosetti. "Large Panels with Common Factors and Spatial Correlation." Journal of Econometrics, 161(2), 2011, 182-202.

Ricardo, D. Principles of Political Economy and Taxation. John Murray, 3rd Edn., 1891.

Sarafidis, V. and T. Wansbeek. "Cross-Sectional Dependence in Panel Data Analysis." Econometric Reviews, 31, 2012, 483-531.

Schumpeter, J. A. Capitalism, socialism and democracy. Routledge, 5th Edn., 1976.

Shaw, K. "Wage Variability in the 1970s: Sectoral Shifts or Cyclical Sensitivity." The Review of Economics and Statistics, 71(1), 1989, 26-36.

Simon, C. "Sectoral Change and Unemployment during the Great Recession, in Historical Perspective." Journal of Regional Science, 54(5), 2014, 828-855.

Swamy, P. A. V. B. "Efficient Inference in a Random Coefficient Regression Model." Econometrica, 38(2), 1970, 311-23.

Wallis, K. F. “Time Series Analysis of Bounded Economic Variables.” Journal of Time Series Analysis, 8(1), 1987, 115-123. 


\section{TABLES AND FiguRES}

\section{Part A: Descriptive Statistics}

TABLE 1:

U.S. States and Abbreviations

\begin{tabular}{lclc}
\hline \hline State & Abbrev. & State & Abbrev. \\
\hline Alabama & AL & Nebraska & NE \\
Arizona & AZ & Nevada & NV \\
Arkansas & AR & New Hampshire & NH \\
California & CA & New Jersey & NJ \\
Colorado & CO & New Mexico & NM \\
Connecticut & CT & New York & NY \\
Delaware & DE & North Carolina & NC \\
Florida & FL & North Dakota & ND \\
Georgia & GA & Ohio & OH \\
Idaho & ID & Oklahoma & OK \\
Illinois & IL & Oregon & OR \\
Indiana & IN & Pennsylvania & PA \\
Iowa & IA & Rhode Island & RI \\
Kansas & KS & South Carolina & SC \\
Kentucky & KY & South Dakota & SD \\
Louisiana & LA & Tennessee & TN \\
Maine & ME & Texas & TX \\
Maryland & MD & Utah & UT \\
Massachusetts & MA & Vermont & VT \\
Michigan & MI & Virginia & VA \\
Minnesota & MN & Washington & WA \\
Mississippi & MS & West Virginia & WV \\
Missouri & MO & Wisconsin & WI \\
Montana & MT & Wyoming & WY \\
\hline$N=48$ & & & \\
$T=264(1990 m 01$ & $-2011 m 12)$ & & \\
Obs =12672 & & & \\
\hline \hline
\end{tabular}


TABLE 2:

Summary Statistics

\begin{tabular}{|c|c|c|c|c|c|c|}
\hline & Mean & Std. Dev. & Minimum & Maximum & Skewness & Kurtosis \\
\hline & \multicolumn{6}{|c|}{ PANEL (A): Sectoral Variables } \\
\hline \multicolumn{7}{|l|}{ Sectoral Employment Shares } \\
\hline Total & 2579.012 & 2621.074 & 195.208 & 15239.910 & 2.233 & 8.955 \\
\hline Mining - Logging - Construction & 139.514 & 147.259 & 11.993 & 976.468 & 2.744 & 11.900 \\
\hline Manufacturing & 322.320 & 322.359 & 8.607 & 1983.681 & 1.937 & 7.918 \\
\hline Trade - Transportations & 509.766 & 511.573 & 40.699 & 2938.358 & 2.128 & 8.234 \\
\hline Information & 61.722 & 80.106 & 3.444 & 598.669 & 3.170 & 15.245 \\
\hline Financial activities & 155.144 & 173.136 & 7.813 & 935.687 & 2.245 & 8.071 \\
\hline Professional activities & 302.468 & 356.647 & 8.484 & 2270.799 & 2.686 & 12.302 \\
\hline Education - Health & 323.131 & 340.305 & 12.528 & 1855.177 & 2.006 & 7.021 \\
\hline Leisure - Hospitality & 239.441 & 248.973 & 23.001 & 1583.518 & 2.525 & 10.842 \\
\hline Other services & 100.239 & 98.989 & 6.512 & 517.006 & 1.810 & 6.338 \\
\hline \multirow[t]{2}{*}{ Government } & 425.105 & 427.011 & 42.156 & 2528.923 & 2.455 & 10.136 \\
\hline & \multicolumn{6}{|c|}{ PANEL (B): Macro Variables } \\
\hline \multicolumn{7}{|l|}{ State Specific } \\
\hline$U_{i, t}$ & 5.539 & 1.900 & 2.100 & 14.200 & 1.122 & 4.593 \\
\hline$U_{i, t}^{\text {Logistic }}$ & -2.890 & 0.346 & -3.842 & -1.799 & 0.218 & 2.952 \\
\hline$U_{i, t}^{L \text { Logarithmic }}$ & -2.948 & 0.327 & -3.863 & -1.952 & 0.162 & 2.903 \\
\hline$\sigma_{i, t}^{13}$ & 0.006 & 0.004 & 0.001 & 0.085 & 5.492 & 69.419 \\
\hline$\sigma_{i, t}^{9}$ & 0.005 & 0.003 & 0.000 & 0.044 & 3.328 & 26.559 \\
\hline$\sigma_{i, t}^{4,2}$ & 0.003 & 0.002 & 0.000 & 0.043 & 4.326 & 43.993 \\
\hline$\sigma_{i, t}^{9}$ purged & 0.000 & 0.003 & -0.005 & 0.038 & 3.328 & 26.482 \\
\hline $\ln \left(P I_{i, t}\right)$ & 11.532 & 1.083 & 8.958 & 14.316 & -0.018 & 2.460 \\
\hline$\Delta \ln \left(P I_{i, t}\right)$ & 0.004 & 0.036 & -0.029 & 0.004 & -0.485 & 8.436 \\
\hline \multicolumn{7}{|l|}{ Common to all States } \\
\hline$\overline{F R_{t}}$ & 3.694 & 2.250 & 0.070 & 8.290 & -0.151 & 2.014 \\
\hline$\Delta F R_{t}$ & -0.031 & 0.193 & -0.960 & 0.530 & -1.336 & 6.760 \\
\hline$H_{t}$ & 0.057 & 0.107 & 0.006 & 0.954 & 4.448 & 28.808 \\
\hline$T B_{t}$ & 3.438 & 2.104 & 0.010 & 7.900 & -0.173 & 2.008 \\
\hline$\Delta T B_{t}$ & -0.029 & 0.201 & -0.860 & 0.460 & -1.083 & 5.348 \\
\hline $\ln \left(G_{t}\right)$ & 8.118 & 0.329 & 7.568 & 8.667 & 0.224 & 1.788 \\
\hline$\Delta \ln \left(G_{t}\right)$ & 0.004 & 0.004 & -0.010 & 0.015 & -0.053 & 4.460 \\
\hline $\ln \left(F G_{t}\right)$ & 7.684 & 0.333 & 7.156 & 8.295 & 0.404 & 1.945 \\
\hline$\Delta \ln \left(F G_{t}\right)$ & 0.004 & 0.006 & -0.016 & 0.022 & 0.102 & 4.511 \\
\hline $\ln \left(S G_{t}\right)$ & 7.287 & 0.348 & 6.646 & 7.782 & -0.082 & 1.680 \\
\hline$\Delta \ln \left(S G_{t}\right)$ & 0.004 & 0.003 & -0.005 & 0.013 & -0.120 & 3.410 \\
\hline
\end{tabular}

Notes: Descriptive statistics for Sectoral Employment and Macroeconomic series for the full sample of 12672 Observations, based on $\mathrm{N}=48$ and $\mathrm{T}=264$. All variables are defined in the Data section of the paper.

TABLE 3:

Lilien's Index $\left(\sigma_{i, t}^{9}\right)$

\begin{tabular}{|c|c|c|c|c|c|c|c|c|c|c|c|c|c|c|c|c|c|c|c|c|c|c|c|c|}
\hline & AL & $\mathrm{AZ}$ & AR & $\mathrm{CA}$ & $\mathrm{CO}$ & CT & $\mathrm{DE}$ & FL & GA & ID & IL & IN & IA & KS & $\mathrm{KY}$ & $\mathrm{LA}$ & ME & MD & MA & MI & MN & MS & $\mathrm{MO}$ & MT \\
\hline 1990 & 0.0049 & 0.0055 & 0.0060 & 0.0034 & 0.0041 & 0.0061 & 0.0134 & 0.0044 & 0.0046 & 0.0083 & 0.0040 & 0.0051 & 0.0041 & 0.0060 & 0.0041 & 0.0050 & 0.0094 & 0.0065 & 0.0057 & 0.0060 & 0.0036 & 0.0068 & 0.0049 & 0.0091 \\
\hline 2000 & 0.0037 & 0.0045 & 0.0042 & 0.0031 & 0.0037 & 0.0031 & 0.0098 & 0.0043 & 0.0052 & 0.0058 & 0.0030 & 0.0039 & 0.0050 & 0.0051 & 0.0050 & 0.0043 & 0.0091 & 0.0058 & 0.0055 & 0.0045 & 0.0035 & 0.0051 & 0.0046 & 0.0053 \\
\hline 2011 & 0.0055 & 0.0047 & 0.0065 & 0.0024 & 0.0045 & 0.0047 & 0.0082 & 0.0032 & 0.0047 & 0.0066 & 0.0027 & 0.0042 & 0.0043 & 0.0060 & 0.0041 & 0.0058 & 0.0059 & 0.0058 & 0.0052 & 0.0053 & 0.0056 & 0.0046 & 0.0046 & 0.0070 \\
\hline $1990-2011$ & 0.0038 & 0.0047 & 0.0042 & 0.0035 & 0.0040 & 0.0044 & 0.0099 & 0.0039 & 0.0040 & 0.0061 & 0.0035 & 0.0040 & 0.0042 & 0.0050 & 0.0043 & 0.0051 & 0.0056 & 0.0041 & 0.0037 & 0.0049 & 0.0038 & 0.0054 & 0.0042 & 0.0062 \\
\hline & $\mathrm{NE}$ & $\mathrm{NV}$ & $\mathrm{NH}$ & NJ & NM & NY & $\mathrm{NC}$ & ND & $\mathrm{OH}$ & $\overline{\mathrm{OK}}$ & $\overline{O R}$ & $\mathrm{PA}$ & RI & SC & SD & $\mathrm{TN}$ & $\mathrm{TX}$ & UT & VT & VA & WA & WV & WI & WY \\
\hline 1990 & 0.0055 & 0.0075 & 0.0081 & 0.0053 & 0.0053 & 0.0041 & 0.0045 & 0.0054 & 0.0040 & 0.0055 & 0.0059 & 0.0035 & 0.0084 & 0.0055 & 0.0068 & 0.0054 & 0.0036 & 0.0043 & 0.0087 & 0.0046 & 0.0047 & 0.0071 & 0.0035 & 0.0085 \\
\hline 2000 & 0.0050 & 0.0062 & 0.0046 & 0.0045 & 0.0047 & 0.0053 & 0.0036 & 0.0062 & 0.0034 & 0.0039 & 0.0034 & 0.0043 & 0.0090 & 0.0046 & 0.0069 & 0.0059 & 0.0023 & 0.0039 & 0.0106 & 0.0052 & 0.0066 & 0.0111 & 0.0034 & 0.0069 \\
\hline 2011 & 0.0050 & 0.0054 & 0.0064 & 0.0048 & 0.0072 & 0.0050 & 0.0035 & 0.0072 & 0.0032 & 0.0050 & 0.0041 & 0.0029 & 0.0080 & 0.0042 & 0.0067 & 0.0047 & 0.0029 & 0.0051 & 0.0066 & 0.0040 & 0.0044 & 0.0061 & 0.0051 & 0.0074 \\
\hline $1990-2011$ & 0.0046 & 0.0062 & 0.0054 & 0.0038 & 0.0056 & 0.0033 & 0.0041 & 0.0061 & 0.0033 & 0.0044 & 0.0039 & 0.0031 & 0.0067 & 0.0045 & 0.0058 & 0.0052 & 0.0027 & 0.0046 & 0.0066 & 0.0037 & 0.0044 & 0.0060 & 0.0036 & 0.0068 \\
\hline
\end{tabular}

Notes: The data shows the averages of Lilien's dispersion index $\left(\sigma_{i, t}^{9}\right)$ for each state using information on the 9 main sectors of the economy (excluding the government sector) in 1990, 2000, 2011 and over the period 1990-2011. See Table 1 for U.S. States Abbreviations. 
TABLE 4:

U.S. Regional Employment Structure (\%)

\begin{tabular}{|c|c|c|c|c|c|c|c|c|c|c|c|c|c|c|c|c|c|c|c|c|c|c|c|c|}
\hline & $\overline{\mathrm{AL}}$ & $\overline{\mathrm{AZ}}$ & $\overline{\mathrm{AR}}$ & $\mathrm{CA}$ & $\mathrm{CO}$ & CT & $\overline{\mathrm{DE}}$ & FL & $\overline{\mathrm{GA}}$ & ID & IL & IN & IA & KS & $\mathrm{KY}$ & $\mathrm{LA}$ & $\mathrm{ME}$ & MD & $\overline{\mathrm{MA}}$ & MI & MN & MS & $\mathrm{MO}$ & MT \\
\hline 1990 (\%) & & & & & & & & & & & & & & & & & & & & & & & & \\
\hline Mining - Lo & 8 & 3 & 4. & 5.45 & 5.29 & 3.92 & 6.23 & 7.73 & 5.50 & 0 & 450 & 4. & 32 & 4.80 & 6.7 & 9.54 & 6.05 & 7.38 & 41 & 93 & 4.05 & 5.08 & 4.31 & 6.25 \\
\hline ant & 22.20 & 1.90 & 23.70 & 5.70 & 1.20 & .60 & .20 & 9.46 & 17.50 & 60 & 30 & 24.00 & .90 & 16.30 & 18.30 & .10 & 40 & 9.14 & .10 & .30 & 6.00 & 24.50 & 16.70 & 6.57 \\
\hline & 19.40 & 20.90 & 21.10 & 9.40 & 0.00 & 19.60 & .40 & 22.70 & 22.30 & .20 & 1.70 & 21.10 & 2.00 & 21.90 & 20.70 & 22.40 & 21.00 & 20.40 & 19.10 & 19.60 & 21.00 & 20.00 & 21.50 & 23.70 \\
\hline Ifor & 33 & 2.20 & 1.92 & 3.1 & 3.43 & 2.60 & 1.44 & 38 & 2.85 & 1.97 & 2. & 1.78 & 2.44 & 2.79 & 1.8 & 1.69 & 1. & 2.18 & 2.93 & 1.77 & 2.54 & 1.39 & 2.85 & 2.16 \\
\hline & 4.90 & 6.65 & 4.34 & 6.55 & 6.88 & 9.47 & .60 & 7.17 & 5.3 & 4.98 & 7.08 & 5.17 & 5.67 & 5.48 & 4.3 & 5.47 & 4.96 & 6.32 & 6.73 & 4.88 & 6.05 & 4.40 & 5.95 & 4.65 \\
\hline ities & 7.20 & 9.63 & 6.22 & 12.00 & 11.80 & 10.40 & 4.50 & 5.80 & 9.50 & 8.50 & 0.80 & 6.20 & 5.63 & 7.70 & 6.70 & 7.30 & 6.29 & 11.90 & 11.50 & 10.10 & 10.00 & 5.48 & 9.30 & 5.24 \\
\hline$d u$ & 7.90 & 9.12 & 9.88 & 8.97 & 8.50 & 12.20 & 9.50 & 11.30 & 8.20 & 8.40 & 0.20 & 9.90 & 12.00 & 9.60 & 11.50 & 10.30 & 12.40 & 10.40 & 15.40 & 10.40 & 11.30 & 8.00 & 10.90 & 11.80 \\
\hline $\mathrm{y}$ & 6.51 & .70 & 7.04 & 84 & 1.00 & 6.66 & 8.00 & 3.20 & 8.05 & 9.53 & 7.4 & 8.2 & 8.27 & 8.03 & 8.1 & 8.00 & 9.00 & 8.51 & 7.94 & 8.38 & 8.45 & 6.00 & 8.80 & 11.80 \\
\hline the & 3.74 & 3.89 & 3.61 & 3.34 & 3.68 & 3.54 & 3.39 & 4.30 & 3.06 & 2.99 & 3.92 & 3.84 & 4.53 & 3.76 & 4.22 & 3.65 & 3.23 & 4.43 & 3.26 & 3.65 & 4.27 & 3.36 & 3.90 & 3.89 \\
\hline Government & 20.00 & 18.40 & 17.20 & 16.60 & 18.20 & 13.00 & 13.80 & 15.80 & 17.80 & 21.10 & 14.50 & 14.90 & 17.90 & 19.60 & 17.50 & 20.50 & 17.90 & 19.40 & 13.70 & 16.00 & 16.30 & 21.70 & 15.80 & 24.00 \\
\hline
\end{tabular}

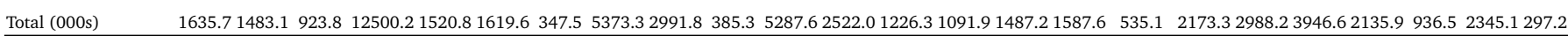

\begin{tabular}{lllllllllllllllllllllllll}
$1990(\%)$ & NE & NV & NH & NJ & NM & NY & NC & ND & OH & OK & OR & PA & RI & SC & SD & TN & TX & UT & VT & VA & WA & WV & WI & WY \\
\cline { 2 - 8 }
\end{tabular}

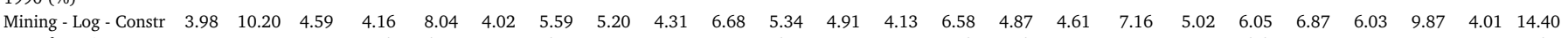
$\begin{array}{llllllllllllllllllllllllllll}\text { Manufacturing } & 13.30 & 3.90 & 19.40 & 14.60 & 6.55 & 12.00 & 26.40 & 5.85 & 21.70 & 13.20 & 16.30 & 18.40 & 21.00 & 22.60 & 11.60 & 22.80 & 13.30 & 14.30 & 16.60 & 13.40 & 15.70 & 13.00 & 22.80 & 4.60\end{array}$ $\begin{array}{lrllllllllllllllllllllllll}\text { Trade - Transport } & 23.00 & 17.90 & 21.50 & 22.90 & 20.30 & 19.10 & 20.30 & 24.30 & 19.70 & 20.90 & 21.10 & 20.20 & 17.10 & 19.70 & 22.30 & 22.00 & 22.20 & 21.20 & 19.80 & 19.90 & 20.20 & 21.50 & 20.00 & 21.00\end{array}$ $\begin{array}{lllllllllllllllllllllllll}\text { Information } & 3.01 & 1.77 & 2.07 & 3.31 & 1.84 & 3.48 & 1.66 & 2.25 & 2.07 & 1.93 & 2.15 & 2.11 & 2.22 & 1.50 & 1.90 & 2.04 & 2.49 & 1.85 & 2.13 & 2.56 & 2.31 & 1.90 & 1.94 & 1.85\end{array}$ $\begin{array}{llllllllllllllllllllllllll}\text { Financial activities } & 6.67 & 5.11 & 6.49 & 6.44 & 4.76 & 9.49 & 4.51 & 4.79 & 5.22 & 5.71 & 5.79 & 6.28 & 5.90 & 4.62 & 5.92 & 5.17 & 6.46 & 4.81 & 5.24 & 4.97 & 5.28 & 4.15 & 5.41 & 3.99\end{array}$ $\begin{array}{llllllllllllllllllllllllll}\text { Professional activities } & 8.40 & 9.50 & 7.20 & 12.10 & 9.80 & 10.50 & 7.70 & 4.50 & 9.30 & 8.20 & 8.20 & 8.80 & 9.40 & 8.60 & 3.86 & 7.60 & 9.00 & 10.30 & 5.50 & 12.00 & 9.20 & 5.19 & 6.70 & 4.47\end{array}$

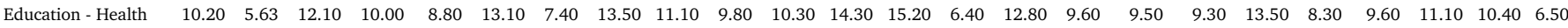

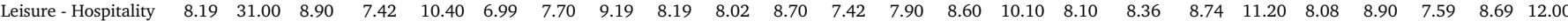
$\begin{array}{lllllllllllllllllllllllll}\text { Other services } & 3.52 & 2.70 & 3.48 & 3.29 & 3.76 & 3.39 & 3.25 & 4.88 & 3.64 & 3.55 & 3.68 & 4.06 & 3.54 & 3.08 & 4.82 & 2.12 & 3.70 & 3.53 & 3.07 & 4.03 & 4.18 & 5.42 & 5.09 & 3.37\end{array}$ $\begin{array}{lllllllllllllllllllllllllll}\text { Government } & 19.60 & 12.20 & 14.30 & 15.90 & 25.80 & 17.90 & 15.50 & 25.50 & 14.80 & 22.10 & 18.50 & 13.60 & 13.80 & 18.30 & 21.90 & 16.00 & 17.80 & 20.80 & 16.90 & 20.00 & 18.60 & 20.20 & 15.00 & 27.80\end{array}$ \begin{tabular}{ccccccccccccccccccccccccc} 
Total (000s) & 730.8 & 620.9 & 508.2 & 3635.5 & 580.4 & 8214.6 & 3125.5 & 265.8 & 4882.3 & 1183.9 & 1255.6 & 5173.0 & 454.1 & 1541.9 & 288.5 & 2196.0 & 7101.0 & 723.6 & 257.7 & 2894.3 & 2142.9 & 630.0 & 2291.4 & 198.5 \\
\hline & AL & AZ & AR & CA & CO & CT & DE & FL & GA & ID & IL & IN & IA & KS & KY & LA & ME & MD & MA & MI & MN & MS & MO & MT \\
\hline
\end{tabular}

$2011(\%)$

$\begin{array}{lllllllllllllllllllllllll}\text { Mining - Log - Constr } & 4.89 & 5.12 & 4.98 & 4.14 & 6.20 & 3.19 & 4.69 & 4.54 & 3.98 & 5.56 & 3.62 & 4.49 & 4.36 & 4.62 & 5.04 & 9.19 & 4.60 & 5.74 & 3.39 & 3.35 & 3.64 & 5.31 & 4.02 & 7.22\end{array}$

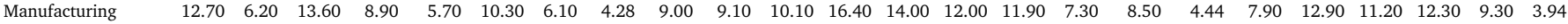

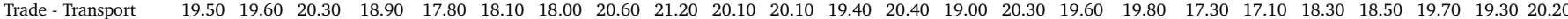
$\begin{array}{lllllllllllllllllllllllll}\text { Information } & 1.25 & 1.52 & 1.26 & 3.07 & 3.17 & 1.94 & 1.38 & 1.85 & 2.51 & 1.55 & 1.77 & 1.21 & 1.89 & 2.08 & 1.49 & 1.25 & 1.38 & 1.66 & 2.58 & 1.36 & 1.97 & 1.09 & 2.20 & 1.70\end{array}$ $\begin{array}{llllllllllllllllllllllllll}\text { Financial activities } & 4.96 & 6.90 & 4.15 & 5.42 & 6.37 & 8.31 & 10.20 & 6.64 & 5.38 & 4.84 & 6.39 & 4.64 & 6.80 & 5.47 & 4.71 & 4.98 & 5.34 & 5.60 & 6.41 & 4.91 & 6.51 & 4.11 & 6.01 & 4.88\end{array}$

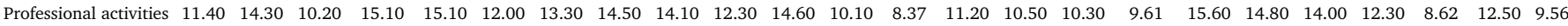
$\begin{array}{lllllllllllllllllllllllll}\text { Education - Health } & 11.60 & 14.80 & 14.40 & 13.00 & 12.10 & 19.40 & 16.00 & 15.20 & 12.90 & 14.30 & 15.00 & 15.10 & 14.60 & 13.80 & 14.30 & 14.80 & 20.30 & 16.10 & 20.90 & 15.80 & 17.50 & 12.40 & 15.70 & 15.00\end{array}$

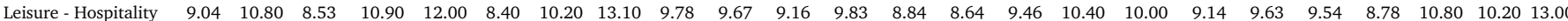
$\begin{array}{llllllllllllllllllllllllll}\text { Other services } & 4.28 & 3.72 & 3.74 & 3.46 & 4.14 & 3.72 & 4.67 & 4.22 & 3.95 & 3.46 & 4.38 & 3.86 & 3.82 & 3.91 & 3.92 & 3.31 & 3.38 & 4.54 & 3.78 & 4.25 & 4.31 & 3.12 & 4.24 & 3.87\end{array}$ $\begin{array}{llllllllllllllllllllllllllll}\text { Government } & 20.40 & 17.10 & 18.90 & 17.10 & 17.40 & 14.70 & 15.40 & 15.10 & 17.20 & 19.20 & 14.80 & 15.00 & 16.90 & 19.30 & 18.40 & 18.90 & 17.10 & 19.90 & 13.50 & 15.70 & 15.20 & 22.60 & 16.50 & 20.60\end{array}$

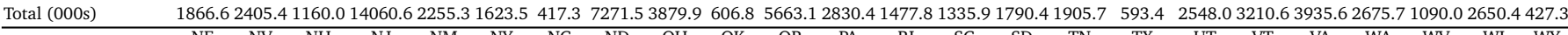

$2011(\%)$

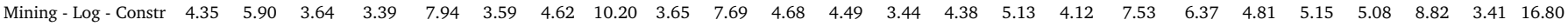

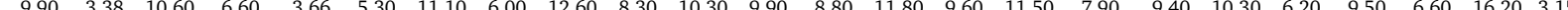

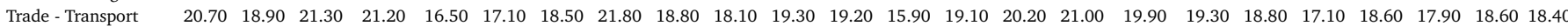
$\begin{array}{lllllllllllllllllllllllllll}\text { Information } & 1.79 & 1.12 & 1.78 & 1.92 & 1.77 & 2.94 & 1.75 & 1.81 & 1.50 & 1.56 & 1.99 & 1.59 & 2.21 & 1.41 & 1.57 & 1.66 & 1.85 & 2.44 & 1.67 & 2.01 & 3.68 & 1.39 & 1.69 & 1.35\end{array}$ $\begin{array}{lllllllllllllllllllllllll}\text { Financial activities } & 7.36 & 4.62 & 5.54 & 6.51 & 4.10 & 7.87 & 5.17 & 5.35 & 5.47 & 5.13 & 5.68 & 5.44 & 6.68 & 5.24 & 6.88 & 5.10 & 6.05 & 5.71 & 4.04 & 4.96 & 4.87 & 3.62 & 5.77 & 3.73\end{array}$ $\begin{array}{lllllllllllllllllllllllll}\text { Professional activities } & 11.00 & 12.40 & 10.50 & 15.60 & 12.40 & 13.10 & 13.00 & 7.66 & 12.70 & 11.20 & 11.50 & 12.50 & 11.80 & 12.40 & 7.02 & 12.10 & 12.70 & 13.20 & 8.31 & 18.00 & 12.00 & 8.27 & 10.30 & 6.13\end{array}$

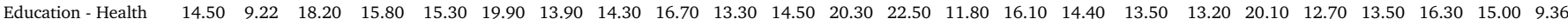

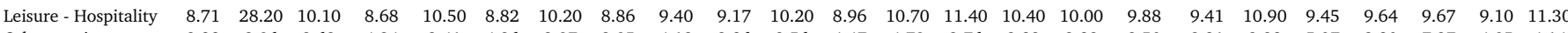
$\begin{array}{llllllllllllllllllllllllll}\text { Other services } & 3.88 & 2.96 & 3.63 & 4.24 & 3.41 & 4.26 & 3.97 & 3.95 & 4.13 & 3.86 & 3.56 & 4.47 & 4.79 & 3.76 & 3.83 & 3.82 & 3.50 & 2.81 & 3.28 & 5.07 & 3.80 & 7.27 & 4.95 & 4.14\end{array}$

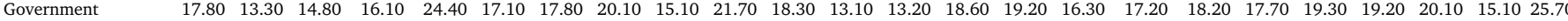

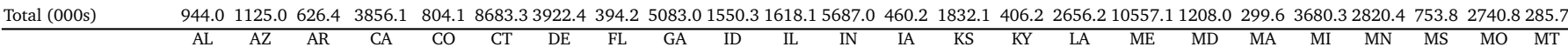
1990:01-2011:12 (\%)

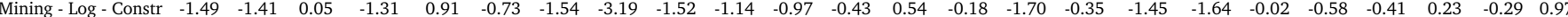
$\begin{array}{llllllllllllllllllllllllll}\text { Trade - Transport } & 0.10 & -1.30 & -0.80 & -0.50 & -2.20 & -1.50 & -1.40 & -2.10 & -1.10 & -2.10 & -1.60 & -1.70 & -1.60 & -2.90 & -0.40 & -2.80 & -1.20 & -3.10 & -2.00 & -1.30 & -2.50 & -0.30 & -2.20 & -3.50\end{array}$

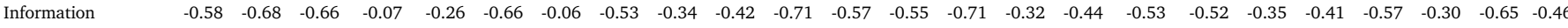
$\begin{array}{lllllllllllllllllllllllllll}\text { Financial activities } & 0.06 & 0.25 & -0.19 & -1.13 & -0.51 & -1.16 & -0.40 & -0.53 & 0.06 & -0.14 & -0.69 & -0.53 & 1.13 & -0.01 & 0.36 & -0.49 & 0.38 & -0.72 & -0.32 & 0.03 & 0.46 & -0.29 & 0.06 & 0.23 & \end{array}$ $\begin{array}{lllllllllllllllllllllllll}\text { Professional activities } & 4.20 & 4.67 & 3.98 & 3.10 & 3.30 & 1.60 & -1.20 & 8.70 & 4.60 & 3.80 & 3.80 & 3.90 & 2.74 & 3.50 & 3.80 & 3.00 & 3.32 & 3.70 & 3.30 & 3.90 & 2.30 & 3.14 & 3.20 & 4.32\end{array}$

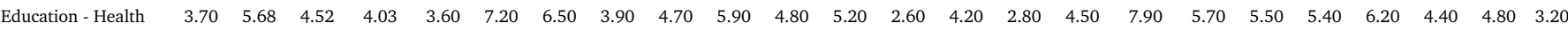
$\begin{array}{llllllllllllllllllllllllll}\text { Leisure - Hospitality } & 2.53 & 0.10 & 1.49 & 2.06 & 1.00 & 1.74 & 2.20 & -0.10 & 1.73 & 0.14 & 1.71 & 1.58 & 0.57 & 0.61 & 1.27 & 2.40 & 1.00 & 0.63 & 1.69 & 1.16 & 0.33 & 4.80 & 1.40 & 1.20\end{array}$ $\begin{array}{lllllllllllllllllllllllllll}\text { Other services } & 0.54 & -0.17 & 0.13 & 0.12 & 0.46 & 0.18 & 1.28 & -0.08 & 0.89 & 0.47 & 0.46 & 0.02 & -0.71 & 0.15 & -0.30 & -0.34 & 0.15 & 0.11 & 0.52 & 0.60 & 0.04 & -0.24 & 0.34 & -0.02\end{array}$ $\begin{array}{llllllllllllllllllllllllll}\text { Government } & 0.40 & -1.30 & 1.70 & 0.50 & -0.80 & 1.70 & 1.60 & -0.70 & -0.60 & -1.90 & 0.30 & 0.10 & -1.00 & -0.30 & 0.90 & -1.60 & -0.80 & 0.50 & -0.20 & -0.30 & -1.10 & 0.90 & 0.70 & -3.40\end{array}$

Total (000s)

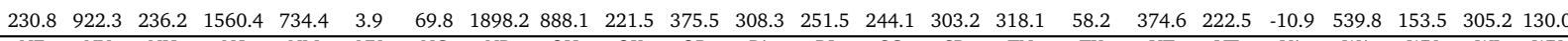
1990:01-2011:12 (\%)

$\begin{array}{lllllllllllllllllllllllllllll}\text { Mining - Log - Constr } & 0.37 & -4.30 & -0.95 & -0.77 & -0.10 & -0.43 & -0.97 & 5.00 & -0.66 & 1.01 & -0.66 & -0.42 & -0.69 & -2.20 & 0.26 & -0.49 & 0.37 & 1.35 & -1.24 & -1.72 & -0.95 & -1.05 & -0.60 & 2.40\end{array}$ $\begin{array}{lllllllllllllllllllllllll}\text { Manufacturing } & -3.40 & -0.52 & -8.80 & -8.00 & -2.89 & -6.70 & -15.30 & 0.15 & -9.10 & -4.90 & -6.00 & -8.50 & -12.20 & -10.80 & -2.00 & -11.30 & -5.40 & -4.90 & -6.30 & -7.20 & -6.20 & -6.40 & -6.60 & -1.45\end{array}$ $\begin{array}{lllllllllllllllllllllllll}\text { Trade - Transport } & -2.30 & 1.00 & -0.20 & -1.70 & -3.80 & -2.00 & -1.80 & -2.50 & -0.90 & -2.80 & -1.80 & -1.00 & -1.20 & -0.60 & -2.10 & -1.00 & -2.30 & -1.90 & -1.00 & -2.80 & -1.60 & -3.60 & -1.40 & -2.60\end{array}$ $\begin{array}{lllllllllllllllllllllllllll}\text { Information } & -1.22 & -0.65 & -0.29 & -1.39 & -0.07 & -0.54 & 0.09 & -0.44 & -0.57 & -0.37 & -0.16 & -0.52 & -0.01 & -0.09 & -0.33 & -0.38 & -0.64 & 0.59 & -0.46 & -0.55 & 1.37 & -0.51 & -0.25 & -0.50\end{array}$ $\begin{array}{llllllllllllllllllllllllll}\text { Financial activities } & 0.69 & -0.49 & -0.95 & 0.07 & -0.66 & -1.62 & 0.66 & 0.56 & 0.25 & -0.58 & -0.11 & -0.84 & 0.78 & 0.62 & 0.96 & -0.07 & -0.41 & 0.90 & -1.20 & -0.01 & -0.41 & -0.53 & 0.36 & -0.26\end{array}$ $\begin{array}{llllllllllllllllllllllllll}\text { Professional activities } & 2.60 & 2.90 & 3.30 & 3.50 & 2.60 & 2.60 & 5.30 & 3.16 & 3.40 & 3.00 & 3.30 & 3.70 & 2.40 & 3.80 & 3.16 & 4.50 & 3.70 & 2.90 & 2.81 & 6.00 & 2.80 & 3.08 & 3.60 & 1.66\end{array}$ $\begin{array}{llllllllllllllllllllllllll}\text { Education - Health } & 4.30 & 3.59 & 6.10 & 5.80 & 6.50 & 6.80 & 6.50 & 0.80 & 5.60 & 3.50 & 4.20 & 6.00 & 7.30 & 5.40 & 3.30 & 4.80 & 4.00 & 3.90 & 6.60 & 4.40 & 3.90 & 5.20 & 4.60 & 2.86\end{array}$

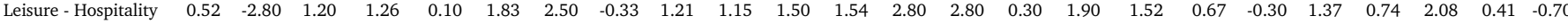
$\begin{array}{llllllllllllllllllllllllll}\text { Other services } & 0.36 & 0.26 & 0.15 & 0.95 & -0.35 & 0.87 & 0.72 & -0.93 & 0.49 & 0.31 & -0.12 & 0.41 & 1.25 & 0.68 & -0.99 & 1.70 & -0.20 & -0.72 & 0.21 & 1.04 & -0.38 & 1.85 & -0.14 & 0.77 & 0.30\end{array}$ $\begin{array}{llllllllllllllllllllllllllll}\text { Government } & -1.80 & 1.10 & 0.50 & 0.20 & -1.40 & -0.80 & 2.30 & -5.40 & 0.30 & -0.40 & -0.20 & -0.50 & -0.60 & 0.30 & -2.70 & 0.30 & -0.60 & -2.60 & 0.80 & -0.70 & 0.60 & -0.10 & 0.10 & -2.10 & 0.71\end{array}$ 


\section{PART B: Data Properties}

TABLE 5:

ADF Unit Root Tests

\begin{tabular}{|c|c|c|c|c|c|c|c|c|c|c|c|c|}
\hline & \multicolumn{2}{|c|}{$F R_{t}$} & \multicolumn{2}{|c|}{$H_{t}$} & \multicolumn{2}{|c|}{$T B_{t}$} & \multicolumn{2}{|c|}{$\ln \left(G_{t}\right)$} & \multicolumn{2}{|c|}{$\ln \left(F G_{t}\right)$} & \multicolumn{2}{|c|}{$\ln \left(S G_{t}\right)$} \\
\hline & Statistic & $p$-value & Statistic & $p$-value & Statistic & $p$-value & Statistic & $p$-value & Statistic & $p$-value & Statistic & $p$-value \\
\hline Levels & -2.095 & 0.247 & $-8.920^{*}$ & 0.000 & -2.097 & 0.246 & -0.327 & 0.918 & 0.269 & 0.976 & -1.778 & 0.390 \\
\hline Differences & $-5.731^{*}$ & 0.000 & $-12.123^{*}$ & 0.000 & $-5.399^{*}$ & 0.000 & $-3.865^{*}$ & 0.003 & $-4.238^{*}$ & 0.000 & $-2.821^{* *}$ & 0.056 \\
\hline
\end{tabular}

Notes: ADF refers to the Augmented Dickey-Fuller unit root test. ${ }^{*}$ and ${ }^{* *}$ indicates rejection of the null hypothesis at the $5 \%$ and $10 \%$ significance levels, respectively. The $5 \%$ and $10 \%$ critical values for the ADF statistics are -2.872 and -2.573 .

TABLE 6:

Panel Unit Root Tests

\begin{tabular}{|c|c|c|c|c|c|c|c|c|c|c|c|c|}
\hline & \multicolumn{2}{|c|}{$U_{i, t}^{\text {Logistic }}$} & \multicolumn{2}{|c|}{$U_{i, t}^{\text {Logarithmic }}$} & \multicolumn{2}{|c|}{$\sigma_{i, t}^{13}$} & \multicolumn{2}{|c|}{$\sigma_{i, t}^{9}$} & \multicolumn{2}{|c|}{$\sigma_{i, t}^{9}$ purged } & \multicolumn{2}{|c|}{$\ln \left(P I_{i, t}\right)$} \\
\hline & Statistic & $p$-value & Statistic & $p$-value & Statistic & $p$-value & Statistic & $p$-value & Statistic & $p$-value & Statistic & $p$-value \\
\hline IPS & $-3.654^{*}$ & 0.000 & $-3.423^{*}$ & 0.000 & $-55.580^{*}$ & 0.000 & $-52.395^{*}$ & 0.000 & $-54.350^{*}$ & 0.000 & 1.420 & 0.922 \\
\hline CIPS & $-2.767^{*}$ & 0.003 & $-2.709^{*}$ & 0.003 & $-32.762^{*}$ & 0.000 & $-32.150^{*}$ & 0.000 & $-32.136^{*}$ & 0.000 & -0.660 & 0.255 \\
\hline
\end{tabular}

Notes: IPS refers to the panel unit root test of Im et al. (2003) and CIPS refers to the panel unit root test of Pesaran (2007) that takes into account cross-sectional dependence among states. ${ }^{*}$ indicates rejection of the null hypothesis at 5\% significance level. The 5\% critical value for the IPS statistics is -1.730 and the $5 \%$ critical value for the CIPS statistics is -2.120 .

TABLE 7:

Cross-Sectional Dependence Tests

\begin{tabular}{|c|c|c|c|c|c|c|}
\hline & $U_{i, t}^{\text {Logistic }}$ & $U_{i, t}^{\text {Logarithmic }}$ & $\sigma_{i, t}^{13}$ & $\sigma_{i, t}^{9}$ & $\sigma_{i, t}^{9}$ purged & $\ln \left(P I_{i, t}\right)$ \\
\hline$C D_{P}$ test & $127.321^{*}$ & $126.065^{*}$ & $147.924^{*}$ & $152.285^{*}$ & $148.459^{*}$ & $295.189 *$ \\
\hline$p$-value & 0.000 & 0.000 & 0.000 & 0.000 & 0.000 & 0.000 \\
\hline$C D_{L M}$ test & $406.707^{*}$ & $398.912^{*}$ & $517.977^{*}$ & $538.868^{*}$ & $511.302^{*}$ & $1951.529^{*}$ \\
\hline$p$-value & 0.000 & 0.000 & 0.000 & 0.000 & 0.000 & 0.000 \\
\hline Abs(Corr) & 0.237 & 0.235 & 0.275 & 0.281 & 0.274 & 0.543 \\
\hline
\end{tabular}

Notes: The $C D_{P}$ test refers to the Cross-Sectional Dependence test of Pesaran (2004) and the $C D_{L M}$ test refers to the scaled version of the Lagrange Multiplier (LM) Cross-Sectional Dependence test of Breusch and Pagan (1980) that is proposed by Pesaran (2004). Abs(Corr) refers to the average absolute pair-wise correlation coefficients. ${ }^{*}$ indicates rejection of the null hypothesis at $5 \%$ significance level. 
TABLE 8:

Poolability Tests

\begin{tabular}{lccccc}
\hline \hline & \multicolumn{2}{c}{$U_{i, t}^{\text {Logistic }}$} & & \multicolumn{2}{c}{$U_{i, t}^{\text {Logarithmic }}$} \\
\cline { 2 - 3 } \cline { 5 - 6 } \cline { 5 - 6 } Chow test & Full & Reduced & & Full & Reduced \\
\hline -value & $3.442^{*}$ & $4.372^{*}$ & & $3.339^{*}$ & $4.181^{*}$ \\
Delta test & 0.000 & 0.000 & & 0.000 & 0.000 \\
$p$-value & $16.821^{*}$ & $11.539^{*}$ & & $16.178^{*}$ & $11.231^{*}$ \\
Delta & 0.000 & 0.000 & & 0.000 & 0.000 \\
$p$-value & $17.081^{*}$ & $11.628^{*}$ & & $16.429^{*}$ & $11.317^{*}$ \\
& 0.000 & 0.000 & & 0.000 & 0.000
\end{tabular}

Notes: Chow refers to the poolability test of Chow (1960). Delta and Delt $a_{a d j}$ refer to the standardized Delta test and the bias adjusted version of the Delta test for slope homogeneity in large panels, proposed by Pesaran and Yamagata (2008). * indicates rejection of the null hypothesis at $5 \%$ significance level.

\section{PART C: Estimation TABles}

TABLE 9:

Lilien's Index and Sectoral Shifts: Aggregate Estimates

\begin{tabular}{|c|c|c|c|c|c|c|c|c|}
\hline & \multicolumn{4}{|c|}{$\overline{U_{t}^{\text {Logistic }}}$} & \multicolumn{4}{|c|}{$U_{t}^{\text {Logarithmic }}$} \\
\hline & OLS & GMM & OLS & GMM & OLS & GMM & OLS & GMM \\
\hline \multirow[t]{2}{*}{$U_{t-1}^{\text {Logistic }}$} & $0.998^{* * *}$ & $0.999^{* *}$ & $0.998^{\text {** }}$ & $0.999^{* *}$ & & & & \\
\hline & (173.34) & (173.56) & $(172.21)$ & (171.93) & & & & \\
\hline \multirow{2}{*}{$U_{t-1}^{\text {Logarithmic }}$} & & & & & $0.998^{* *}$ & $0.999^{* *}$ & $0.998^{* *}$ & $0.999^{* *}$ \\
\hline & & & & & (173.46) & (173.67) & $(172.65)$ & (172.34) \\
\hline \multirow[t]{2}{*}{$\sigma_{t}^{9}$} & $5.753^{* *}$ & $5.202^{* *}$ & & & $5.295^{* *}$ & $4.820^{* *}$ & & \\
\hline & $(2.51)$ & $(2.32)$ & & & $(2.48)$ & $(2.30)$ & & \\
\hline$\sigma_{t}^{13}$ & & & $(2.02)$ & (1.69) & & & $(2.02)$ & $(1.72)$ \\
\hline \multirow{2}{*}{$\Delta \ln \left(P I_{t}\right)$} & -0.300 & -0.286 & -0.373 & -0.331 & -0.279 & -0.267 & -0.346 & -0.309 \\
\hline & $(-0.99)$ & $(-0.95)$ & $(-1.18)$ & $(-1.05)$ & $(-0.99)$ & $(-0.95)$ & $(-1.18)$ & $(-1.06)$ \\
\hline \multirow[t]{2}{*}{$\Delta F R_{t}$} & $-0.026^{* *}$ & $-0.026^{* *}$ & $-0.026^{* *}$ & $-0.026^{* *}$ & $-0.025^{* *}$ & $-0.025^{* *}$ & $-0.025^{* *}$ & $-0.025^{* *}$ \\
\hline & $(-2.50)$ & $(-2.50)$ & $(-2.47)$ & $(-2.51)$ & $(-2.50)$ & $(-2.49)$ & $(-2.47)$ & $(-2.50)$ \\
\hline \multirow[t]{2}{*}{$H_{t}$} & $0.048^{* *}$ & $0.047^{* *}$ & $0.047^{* *}$ & $0.047^{* *}$ & $0.045^{* *}$ & $0.045^{* *}$ & $0.045^{* *}$ & $0.044^{* *}$ \\
\hline & $(3.90)$ & (3.85) & (3.69) & (3.63) & (3.90) & (3.84) & (3.69) & (3.64) \\
\hline$\Delta \ln \left(G_{t}\right)$ & 0.463 & 0.473 & 0.532 & 0.530 & 0.428 & 0.440 & 0.491 & 0.492 \\
\hline Obs & 263 & 261 & 263 & 261 & 263 & 261 & 263 & 261 \\
\hline$R M S E$ & 0.0266 & 0.0266 & 0.0267 & 0.0268 & 0.0251 & 0.0251 & 0.0252 & 0.0252 \\
\hline Hansen $J$ & & 0.130 & & 0.083 & & 0.138 & & 0.090 \\
\hline
\end{tabular}

Notes: Aggregate time series estimates using OLS and GMM estimation methods. All estimations were carried out using Newey-West HAC robust standard errors. $t$-statistics in parentheses. $R M S E$ refers to the root mean squared error. Hansen $J$ refers to the $p$-value of the Hansen test for the validity of over-identifying restrictions. ${ }^{*}$ and ${ }^{* *}$ denotes significance at the $10 \%$ and $5 \%$ significance levels, respectively. 
TABLE 10:

Assumptions about Panel Estimators

\begin{tabular}{|c|c|c|c|}
\hline & & \multicolumn{2}{|c|}{ Parameter Heterogeneity } \\
\hline & & Homogeneity & Heterogeneity \\
\hline \multirow{2}{*}{ Cross-Sectional Correlation } & Independence & BB GMM & MG \\
\hline & Dependence & DK POLS, DK FE & CCEMG, AMG, dynCCEMG \\
\hline
\end{tabular}

Notes: BB GMM - Blundell and Bond (1998) System GMM estimator, MG - Pesaran and Smith's (1995) Mean Group estimator, DK POLS and DK FE - Driscoll and Kraay's (1998) Pooled OLS and Fixed Effects estimators, CCEMG - Pesaran's (2006) Common Correlated Effects Mean Group estimator, AMG - Bond and Eberhardt's (2009) Augmented Mean Group estimator, dynCCEMG - Chudik and Pesaran's (2015a) Dynamic Common Correlated Effects Mean Group estimator.

TABLE 11:

Lilien's Index and Sectoral Shifts: Homogeneous Parameter Estimates

\begin{tabular}{|c|c|c|c|c|c|c|}
\hline & \multicolumn{3}{|c|}{$U_{i t}^{\text {Logistic }}$} & \multicolumn{3}{|c|}{$U_{i t}^{\text {Logarithmic }}$} \\
\hline & DK POLS & DK FE & BB GMM & DK POLS & DK FE & BB GMM \\
\hline \multirow{2}{*}{$U_{i, t-1}^{\text {Logistic }}$} & $0.997^{* *}$ & $0.995^{* *}$ & $0.999^{* *}$ & & & \\
\hline & (455.88) & (329.66) & (787.07) & & & \\
\hline \multirow{2}{*}{$U_{i, t-1}^{\text {Logarithmic }}$} & & & & $0.997^{\text {** }}$ & $0.995^{\text {** }}$ & $0.999^{* *}$ \\
\hline & & & & (456.09) & (328.64) & (795.71) \\
\hline \multirow{2}{*}{$\sigma_{i, t}^{\text {purged }}$} & $0.658^{*}$ & $0.819^{* *}$ & $0.723^{* *}$ & $0.609^{*}$ & $0.758^{* *}$ & $0.670^{* *}$ \\
\hline & (1.97) & $(2.11)$ & (3.19) & (1.97) & $(2.11)$ & $(3.20)$ \\
\hline \multirow[t]{2}{*}{$\Delta \ln \left(P I_{i, t}\right)$} & $-1.654^{* *}$ & $-1.705^{* *}$ & $-2.029^{* *}$ & $-1.552^{* *}$ & $-1.600^{\text {** }}$ & $-1.903^{* *}$ \\
\hline & $(-3.57)$ & $(-3.69)$ & $(-14.38)$ & $(-3.60)$ & $(-3.73)$ & $(-14.54)$ \\
\hline \multirow[t]{2}{*}{$\Delta F R_{t}$} & $-0.025^{* *}$ & $-0.025^{* *}$ & $-0.024^{* *}$ & $-0.024^{* *}$ & $-0.024^{* *}$ & $-0.023^{* *}$ \\
\hline & $(-5.48)$ & $(-5.52)$ & $(-17.82)$ & $(-5.52)$ & $(-5.56)$ & $(-17.85)$ \\
\hline \multirow[t]{2}{*}{$H_{t}$} & $0.038^{* *}$ & $0.038^{* *}$ & $0.039^{* *}$ & $0.036^{* *}$ & $0.035^{\text {** }}$ & $0.036^{* *}$ \\
\hline & (3.98) & (3.95) & (11.45) & (4.03) & $(4.00)$ & (11.38) \\
\hline \multirow[t]{2}{*}{$\Delta \ln \left(G_{t}\right)$} & $0.859^{* *}$ & $0.843^{* *}$ & $0.879^{* *}$ & $0.803^{\text {** }}$ & $0.788^{\text {*** }}$ & $0.823^{* *}$ \\
\hline & (3.52) & (3.45) & (13.99) & (3.52) & $(3.46)$ & (14.06) \\
\hline Obs & 12624 & 12624 & 12624 & 12624 & 12624 & 12624 \\
\hline$N$ & 48 & 48 & 48 & 48 & 48 & 48 \\
\hline$T$ & 263 & 263 & 263 & 263 & 263 & 263 \\
\hline$R M S E$ & 0.0254 & 0.0255 & 0.0255 & 0.0254 & 0.0255 & 0.0241 \\
\hline Hansen $J$ & & & 1.000 & & & 1.000 \\
\hline$A R(1)$ & & & 0.000 & & & 0.000 \\
\hline
\end{tabular}

Notes: DK POLS and DK FE - Driscoll and Kraay's (1998) Pooled OLS and Fixed Effects estimators. BB GMM - Blundell and Bond (1998) System GMM estimator. $t$-statistics in parentheses. All estimations were carried out using robust standard errors. RMSE refers to the root mean squared error. Hansen $J$ refers to the $p$-value of the Hansen test for the validity of over-identifying restrictions. $A R(1)$ refers to the $p$-value of the test for first-order residual serial correlation. ${ }^{*}$ and ${ }^{* *}$ denotes significance at the $10 \%$ and $5 \%$ significance levels, respectively. 
TABLE 12:

Lilien's Index and Sectoral Shifts: Heterogeneous Parameter Estimates

\begin{tabular}{|c|c|c|c|c|c|c|c|c|c|c|c|c|c|c|c|c|c|c|}
\hline & \multicolumn{9}{|c|}{$\overline{U_{i t}^{\text {Log istic }}}$} & \multicolumn{9}{|c|}{$\overline{U_{i t}^{\text {Logarithmic }}}$} \\
\hline & MG & AMG & CCEMG & $\operatorname{CCEMG~}_{T}$ & dynCCEMG $_{1}$ & dynCCEMG $_{6}$ & CCEMG $^{W}$ & $\operatorname{CCEMG}_{T}^{W}$ & dynCCEMG $_{1}^{W}$ & MG & AMG & CCEMG & CCEMG $_{T}$ & dynCCEMG $_{1}$ & dynCCEMG $_{6}$ & CCEMG $^{W}$ & CCEMG $_{T}^{W}$ & dynCCEMG \\
\hline \multirow{2}{*}{$\overline{\overline{U_{i, t}^{\text {Log istic }}}}$} & $0.993^{\text {ke* }}$ & $0.964^{* *}$ & $0.980^{\text {*** }}$ & $0.970^{* * *}$ & $0.981^{* * *}$ & $0.977^{* * *}$ & $0.974^{* *}$ & $0.967^{* *}$ & $0.976^{* * *}$ & & & & & & & & & \\
\hline & $(853.50)$ & $(242.90)$ & (386.34) & (237.78) & (390.58) & $(245.04)$ & (275.79) & (225.47) & $(274.81)$ & & & & & & & & & \\
\hline \multirow[t]{2}{*}{$U_{i, t}^{\text {Logarithmic }}$} & & & & & & & & & & $0.993^{* *}$ & $0.964^{* *}$ & $0.981^{* *}$ & $0.970^{* * *}$ & $0.981^{* *}$ & $0.977^{* *}$ & $0.974^{* *}$ & $0.967^{* *}$ & $0.976^{* *}$ \\
\hline & & & & & & & & & & $(882.98)$ & (244.87) & (391.43) & $(242.81)$ & (393.54) & (246.95) & $(274.61)$ & (225.16) & $(273.75)$ \\
\hline \multirow[t]{2}{*}{$\sigma_{i, t}^{\text {purged }}$} & $0.877^{\text {k* }}$ & $0.843^{* *}$ & $0.406 * *$ & $0.412^{* * *}$ & $0.433^{* * *}$ & $0.491^{* * *}$ & $0.464^{* * *}$ & $0.511^{* *}$ & $0.424^{* * k}$ & $0.813^{* *}$ & $0.781^{* *}$ & $0.377^{* * *}$ & $0.381^{* *}$ & $0.402^{* * *}$ & $0.456^{* * *}$ & $0.432^{* * *}$ & $0.477^{* * *}$ & $0.396^{* * *}$ \\
\hline & (4.67) & (4.58) & (2.27) & (1.99) & (2.09) & $(2.15)$ & (3.72) & (3.63) & $(2.86)$ & (4.67) & (4.58) & (2.26) & (1.99) & (2.09) & (2.16) & (3.70) & (3.63) & (2.84) \\
\hline \multirow[t]{2}{*}{$\Delta \ln \left(P I_{i, t}\right)$} & $-1.961^{* * *}$ & $-1.813^{* *}$ & $-0.452^{2 * *}$ & $-0.421^{* *}$ & $-0.436^{* * *}$ & $-0.434^{* *}$ & $-0.527^{* *}$ & $-0.471^{* *}$ & $-0.412^{* *}$ & $-1.835^{* *}$ & $-1.696^{* * *}$ & $-0.432^{* *}$ & $-0.402^{* *}$ & $-0.416^{* *}$ & $-0.416^{* * k}$ & $-0.499^{* *}$ & $-0.446^{6 *}$ & $-0.390^{* * *}$ \\
\hline & $(-12.96)$ & $(-10.98)$ & $(-2.55)$ & $(-2.42)$ & $(-2.53)$ & $(-2.23)$ & $(-3.74)$ & $(-3.23)$ & $(-3.08)$ & $(-13.02)$ & $(-11.07)$ & $(-2.60)$ & $(-2.46)$ & $(-2.56)$ & $(-2.27)$ & $(-3.74)$ & $(-3.22)$ & $(-3.07)$ \\
\hline \multirow[t]{2}{*}{$\Delta F R_{t}$} & $-0.024^{* * *}$ & $-0.017^{* *}$ & 0.000 & 0.000 & 0.000 & 0.000 & $-0.007^{* *}$ & $-0.007^{* *}$ & $-0.004^{* *}$ & $-0.023^{* * *}$ & $-0.016^{* * *}$ & 0.000 & 0.000 & 0.000 & 0.000 & $-0.007^{* *}$ & $-0.007^{* * *}$ & $-0.004^{* * *}$ \\
\hline & $(-17.98)$ & $(-10.10)$ & $(0.16)$ & $(0.21)$ & $(0.21)$ & (0.18) & $(-3.31)$ & $(-3.10)$ & $(-2.11)$ & $(-18.02)$ & $(-10.10)$ & (0.16) & $(0.21)$ & $(0.21)$ & $(0.17)$ & $(-3.36)$ & $(-3.16)$ & $(-2.14)$ \\
\hline \multirow[t]{2}{*}{$H_{t}$} & $0.038^{* * *}$ & $0.034^{* *}$ & 0.001 & 0.001 & 0.000 & 0.000 & $0.013^{* *}$ & $0.013^{* *}$ & 0.004 & $0.035^{* * *}$ & $0.032^{* *}$ & 0.001 & 0.001 & 0.000 & 0.000 & $0.012^{* *}$ & $0.013^{* *}$ & 0.004 \\
\hline & (11.30) & (10.40) & $(0.21)$ & $(0.37)$ & $(0.10)$ & (0.14) & (3.44) & (3.53) & (1.14) & (11.24) & (10.35) & $(0.21)$ & $(0.36)$ & $(0.09)$ & $(0.13)$ & (3.48) & (3.56) & (1.13) \\
\hline \multirow[t]{2}{*}{$\Delta \ln \left(G_{t}\right)$} & $0.818^{* * *}$ & $0.809^{* *}$ & -0.021 & -0.019 & 0.001 & -0.011 & $0.279^{* * *}$ & $0.279^{* *}$ & $0.103^{*}$ & $0.766^{* * *}$ & $0.757^{* *}$ & -0.020 & -0.018 & 0.001 & -0.011 & $0.264^{* *}$ & $0.265^{* *}$ & $0.097^{*}$ \\
\hline & (16.65) & (15.76) & $(-0.38)$ & $(-0.34)$ & $(0.01)$ & $(-0.13)$ & $(4.92)$ & (4.91) & (1.73) & (16.63) & (15.73) & $(-0.38)$ & $(-0.33)$ & $(0.01)$ & $(-0.13)$ & (4.98) & (4.98) & (1.73) \\
\hline$O b s$ & 12624 & 12624 & 12624 & 12624 & 12576 & 12336 & 12624 & 12624 & 12576 & 12624 & 12624 & 12624 & 12624 & 12576 & 12336 & 12624 & 12624 & 12576 \\
\hline$N$ & 48 & 48 & 48 & 48 & 48 & 48 & 48 & 48 & 48 & 48 & 48 & 48 & 48 & 48 & 48 & 48 & 48 & 48 \\
\hline$T$ & 263 & 263 & 263 & 263 & 262 & 257 & 263 & 263 & 262 & 263 & 263 & 263 & 263 & 262 & 257 & 263 & 263 & 262 \\
\hline RMSE & 0.0244 & 0.0239 & 0.0208 & 0.0206 & 0.0203 & 0.0187 & 0.0208 & 0.0206 & 0.0201 & 0.0231 & 0.0226 & 0.0197 & 0.0195 & 0.0192 & 0.0177 & 0.0197 & 0.0196 & 0.0191 \\
\hline
\end{tabular}

Notes: MG - Pesaran and Smith's (1995) Mean Group estimator. AMG - Bond and Eberhardt's (2009) Augmented Mean Group estimator CCEMG and CCEMG ${ }_{T}$ - Pesaran's (2006) Common Correlated Effects Mean Group estimator (without and with state-specific linear trend). dynCCEMG $_{1}$ and dynCCEMG 6 - Chudik and Pesaran's (2015a) Dynamic Common Correlated Effects Mean Group estimator (augmented with one and six additional lags of the cross-section averages). CCEMG ${ }^{W}, \mathrm{CCEMG}_{T}^{W}$ and dynCCEMG ${ }_{1}^{W}$ - 'neighbour' weighted versions of the CCEMG and dynCCEMG estimators. $t$-statistics in parentheses. RMSE refers to the root mean squared error. ${ }^{*}$ and ${ }^{* *}$ denotes significance at the $10 \%$ and $5 \%$ significance levels, respectively.

TABLE 13:

Lilien's Index and Sectoral Shifts: Robustness Checks

\begin{tabular}{|c|c|c|c|c|c|c|c|c|}
\hline & (1) & (2) & (3) & (4) & (5) & (6) & (7) & (8) \\
\hline \multirow{2}{*}{$U_{i, t-1}^{\text {Logistic }}$} & $0.981^{\text {*** }}$ & $0.980^{* *}$ & $0.981^{* *}$ & $0.982^{* *}$ & $0.982^{* *}$ & $0.980^{* *}$ & $0.980^{* *}$ & $0.980^{* *}$ \\
\hline & $(390.58)$ & $(390.44)$ & (412.94) & $(368.79)$ & (358.09) & $(390.64)$ & $(378.88)$ & $(362.55)$ \\
\hline \multirow{2}{*}{$\sigma_{i, t}^{\text {purged }}$} & $0.433^{* * *}$ & & & $0.455^{* *}$ & & & $0.435^{* *}$ & \\
\hline & (2.09) & & & $(2.21)$ & & & (2.14) & \\
\hline \multirow{2}{*}{$\sigma_{i, t}^{\text {unpurged }}$} & & $0.429^{* *}$ & & & & & & \\
\hline & & (2.13) & & & & & & \\
\hline \multirow{2}{*}{$\sigma_{i, t}^{\text {purged }(P I)}$} & & & $0.447^{* *}$ & & & & & \\
\hline & & & (2.17) & & & & & \\
\hline \multirow[t]{2}{*}{$\sigma_{i, t}^{\text {purged(TB) }}$} & & & & & $0.428^{* *}$ & & & \\
\hline & & & & & $(2.02)$ & & & \\
\hline \multirow{2}{*}{$\sigma_{i, t}^{\text {purged }(A L L)}$} & & & & & & $0.429^{* *}$ & & \\
\hline & & & & & & $(2.12)$ & & \\
\hline \multirow{2}{*}{$\sigma_{i, t}^{\text {purged(13) }}$} & & & & & & & & $0.344^{*}$ \\
\hline & & & & & & & & (1.89) \\
\hline \multirow{2}{*}{$\Delta \ln \left(P I_{i, t}\right)$} & $-0.436^{\text {*** }}$ & $-0.465^{* *}$ & $-0.542^{* *}$ & & & $-0.483^{\text {** }}$ & $-0.463^{* *}$ & $-0.492^{* *}$ \\
\hline & $(-2.53)$ & $(-2.72)$ & $(-3.31)$ & & & $(-2.91)$ & $(-2.72)$ & $(-2.94)$ \\
\hline \multirow{2}{*}{$\Delta F R_{t}$} & 0.000 & 0.000 & & 0.000 & & 0.000 & 0.000 & 0.000 \\
\hline & $(0.21)$ & $(0.13)$ & & $(0.01)$ & & $(0.14)$ & $(0.11)$ & $(0.18)$ \\
\hline \multirow[t]{2}{*}{$H_{t}$} & 0.000 & 0.001 & & 0.000 & & 0.001 & 0.001 & 0.001 \\
\hline & $(0.10)$ & $(0.23)$ & & $(0.07)$ & & $(0.23)$ & $(0.27)$ & $(0.29)$ \\
\hline \multirow[t]{2}{*}{$\Delta T B_{t}$} & & & & & -0.000 & & & \\
\hline & & & & & $(-0.03)$ & & & \\
\hline \multirow[t]{2}{*}{$H_{t}^{T B}$} & & & & & -0.000 & & & \\
\hline & & & & & $(-0.12)$ & & & \\
\hline \multirow[t]{2}{*}{$\Delta \ln \left(G_{t}\right)$} & 0.001 & -0.016 & & & & -0.016 & & -0.021 \\
\hline & $(0.01)$ & $(-0.28)$ & & & & $(-0.28)$ & & $(-0.38)$ \\
\hline \multirow[t]{2}{*}{$\Delta \ln \left(F G_{t}\right)$} & & & & & & & 0.003 & \\
\hline & & & & & & & $(0.09)$ & \\
\hline \multirow[t]{2}{*}{$\Delta \ln \left(S G_{t}\right)$} & & & & & & & -0.049 & \\
\hline & & & & & & & $(-0.58)$ & \\
\hline Obs & 12576 & 12576 & 12576 & 12576 & 12576 & 12576 & 12576 & 12576 \\
\hline$N$ & 48 & 48 & 48 & 48 & 48 & 48 & 48 & 48 \\
\hline$T$ & 262 & 262 & 262 & 262 & 262 & 262 & 262 & 262 \\
\hline$R M S E$ & 0.0203 & 0.0205 & 0.0208 & 0.0208 & 0.0208 & 0.0205 & 0.0204 & 0.0204 \\
\hline
\end{tabular}

Notes: Estimations are based on the dynCCEMG ${ }_{1}$ - Chudik and Pesaran's (2015a) Dynamic Common Correlated Effects Mean Group estimator (augmented with a reduced number of the first lag of the cross-section averages). $t$-statistics in parentheses. RMSE refers to the root mean squared error. * and ${ }^{* *}$ denotes significance at the $10 \%$ and $5 \%$ significance levels, respectively. 
TABLE 14:

Lilien's Index and Sectoral Shifts: Alternative Sectoral Decomposition

\begin{tabular}{|c|c|c|c|c|c|c|c|c|c|c|c|c|c|c|c|c|c|c|c|c|}
\hline & \multicolumn{10}{|c|}{$\overline{\overline{U_{i t}^{\text {Logistic }}}}$} & \multicolumn{10}{|c|}{$\overline{U_{i t}^{\text {Logarithmic }}}$} \\
\hline & \multicolumn{2}{|c|}{$\sigma_{i t}^{13 \text { purged }}$} & \multicolumn{2}{|c|}{$\sigma_{i t}^{10 \text { purged }}$} & \multicolumn{2}{|c|}{$\sigma_{i t}^{\text {it purged }}$} & \multicolumn{2}{|c|}{$\sigma_{i t}^{7 \text { purged }}$} & \multicolumn{2}{|c|}{$\sigma_{i t}^{4 \text { purged }}$} & \multicolumn{2}{|c|}{$\sigma_{i t}^{13 \text { purged }}$} & \multicolumn{2}{|c|}{$\sigma_{i t}^{10 \text { purged }}$} & \multicolumn{2}{|c|}{$\sigma_{i t}^{9 \text { purged }}$} & \multicolumn{2}{|c|}{$\sigma_{i t}^{7 \text { purged }}$} & \multicolumn{2}{|c|}{$\sigma_{i t}^{4 \text { purged }}$} \\
\hline & DK FE & CCEMG & DK FE & CCEMG & DK FE & CCEMG & DK FE & CCEMG & DK FE & CCEMG & DK FE & CCEMG & DK FE & CCEMG & DK FE & CCEMG & DK FE & CCEMG & DK FE & CCEMG \\
\hline \multirow{2}{*}{$\overline{U_{i, t}^{\text {Logistic }}}$} & $0.995^{* * *}$ & $0.980^{* *}$ & $0.995^{* *}$ & $0.980^{* * *}$ & $0.995^{* *}$ & $0.980^{* * *}$ & $0.995^{* * *}$ & $0.980^{* * *}$ & $0.995^{* *}$ & $0.980^{* * *}$ & & & & & & & & & & \\
\hline & (329.78) & $(362.41)$ & (330.79) & (371.93) & (329.66) & (390.44) & (331.03) & (393.62) & (333.93) & $(374.01)$ & & & & & & & & & & \\
\hline \multirow{2}{*}{$U_{i, t 1}^{\text {Logarithmic }}$} & & & & & & & & & & & $0.995^{* *}$ & $0.980^{* * *}$ & $0.995^{* *}$ & $0.980^{* * *}$ & $0.995^{* *}$ & $0.980^{* * *}$ & $0.995^{* * *}$ & $0.980^{* *}$ & $0.995^{* *}$ & $0.980^{* *}$ \\
\hline & & & & & & & & & & & (328.93) & (366.10) & (329.93) & (375.41) & (328.64) & (394.03) & (329.94) & (397.11) & (332.51) & $(378.24)$ \\
\hline \multirow[t]{2}{*}{$\sigma_{i, t}^{\text {purged }}$} & $0.497^{*}$ & $0.344^{*}$ & $0.727^{* *}$ & $0.365^{* *}$ & $0.819^{* *}$ & $0.429^{* *}$ & $0.797^{k *}$ & $0.406^{* * *}$ & $1.055^{* *}$ & $0.641^{* *}$ & $0.461^{*}$ & $0.319^{*}$ & $0.676^{* *}$ & $0.339 * *$ & $0.758^{* *}$ & $0.399^{* * *}$ & $0.797^{k * *}$ & $0.406^{* *}$ & $1.055^{* * *}$ & $0.641^{* x}$ \\
\hline & (1.76) & (1.89) & (2.04) & (2.00) & (2.11) & (2.13) & (2.38) & (2.24) & (2.68) & (2.19) & (1.76) & (1.89) & (1.98) & (2.05) & (2.01) & (2.11) & $(2.38)$ & (2.24) & (2.68) & (2.19) \\
\hline$O b s$ & 12576 & 12576 & 12576 & 12576 & 12576 & 12576 & 12576 & 12576 & 12576 & 12576 & 12576 & 12576 & 12576 & 12576 & 12576 & 12576 & 12576 & 12576 & 12576 & 12576 \\
\hline$N$ & 48 & 48 & 48 & 48 & 48 & 48 & 48 & 48 & 48 & 48 & 48 & 48 & 48 & 48 & 48 & 48 & 48 & 48 & 48 & 48 \\
\hline$T$ & 262 & 262 & 262 & 262 & 262 & 262 & 262 & 262 & 262 & 262 & 262 & 262 & 262 & 262 & 262 & 262 & 262 & 262 & 262 & 262 \\
\hline RMSE & 0.0255 & 0.0204 & 0.0254 & 0.0205 & 0.0255 & 0.0205 & 0.0255 & 0.0206 & 0.0254 & 0.0205 & 0.0240 & 0.0193 & 0.0240 & 0.0194 & 0.0240 & 0.0194 & 0.0240 & 0.0195 & 0.0240 & 0.0194 \\
\hline
\end{tabular}

Notes: DK FE denotes the Driscoll and Kraay's (1998) Fixed Effects estimator and the CCEMG denotes the dynCCEMG ${ }_{1}-$ Chudik and Pesaran's (2015a) Dynamic Common Correlated Effects Mean Group estimator (augmented with a reduced number of the first lag of the cross-section averages). $t$-statistics in parentheses. RMSE refers to the root mean squared error. ${ }^{*}$ and ${ }^{* *}$ denotes significance at the $10 \%$ and $5 \%$ significance levels, respectively.

\section{PART D: Figures}

FIGURE 1:

Unemployment Rate and Lilien's Index for the U.S. Agregate, 1990:M1-2011:M12.

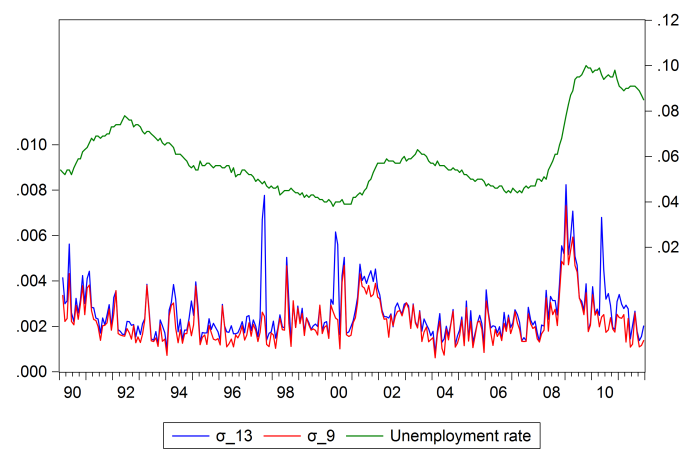

(a) $\sigma_{t}^{13}$ and $\sigma_{t}^{9}$

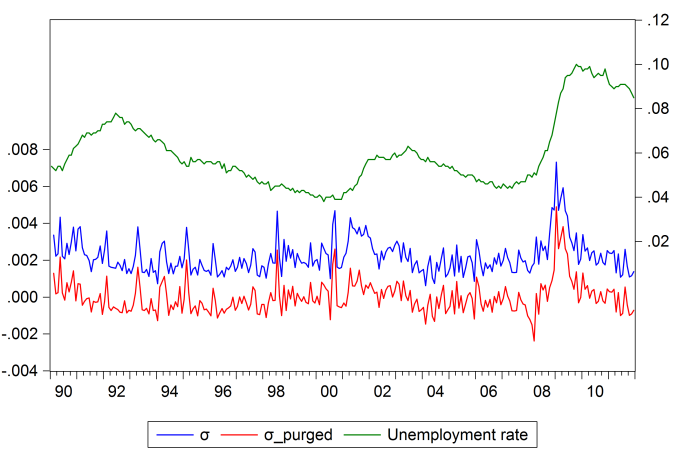

(b) $\sigma_{t}^{9}$ and $\sigma_{t \text { purged }}^{9}$ 


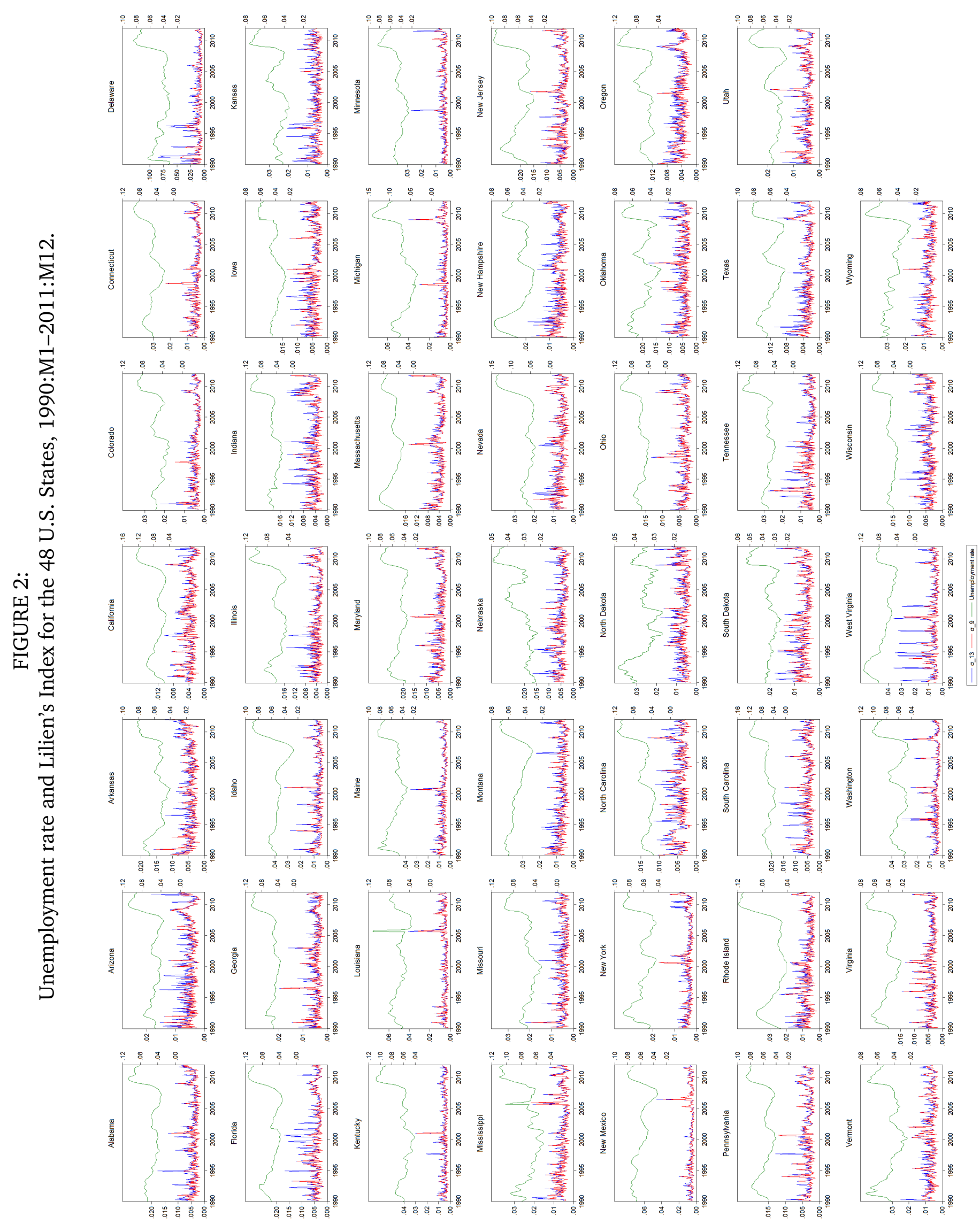




\section{PART E: APPENDIX}

\section{A. Poolability Tests}

An important issue for the estimation of panel data models is the assumption of common slope coefficients across regions, i.e. that $\beta_{i}=\beta$ with $i=1,2, \ldots, N$. Following Baltagi (2008), this can be tested by a simple Chow test, see Chow (1960), that is extended to the case of $N$ linear regressions. The test for the poolability of the data across regions simply compares the restricted residual sum of squares $\left(R S S^{r}\right)$ of the fixed effects model with the unrestricted residual sum of squares $\left(R S S^{u}\right)$ obtained by the region-specific OLS regressions. Under the null hypothesis of poolability across regions the Chow test can be defined as:

$$
F=\frac{\left(R S S^{r}-R S S^{u}\right) /(N-1) k}{R S S^{u} / N(T-k-1)}
$$

where, under the null of homogeneity, the Chow test is distributed as an $F$-statistic with $(N-1) k$ and $N(T-k-1)$ degrees of freedom, and is valid for panels where $N$ is small relative to $T$, as in our case.

Pesaran and Yamagata (2008) proposed a standardized version of Swamy's (1970) statistic in order to test for slope homogeneity in large panels (where $N$ and $T$ are both large). The standardized Delta test statistic $(\tilde{\Delta})$ can be defined by

$$
\tilde{\Delta}=\sqrt{N}\left(\frac{N^{-1} \tilde{S}-k}{\sqrt{2 k}}\right),
$$

and the bias adjusted version of the Delta test statistic is

$$
\tilde{\Delta}_{a d j}=\sqrt{N}\left(\frac{N^{-1} \tilde{S}-E\left(\tilde{z}_{i T}\right)}{\sqrt{\operatorname{Var}\left(\tilde{z}_{i T}\right)}}\right),
$$

where $E\left(\tilde{z}_{i T}\right)=k$ and $\operatorname{Var}\left(\tilde{z}_{i T}\right)=\frac{2 k(T-k-1)}{T+1}$, and $\tilde{S}$ is the modified version of Swamy's (1970) statistic that based on the dispersion of individual slope estimates from a weighted Fixed Effects pooled estimator. The Delta test and its bias adjusted version have an asymptotic standard normal distribution under homogeneity null and as $(N, T) \rightarrow \infty$ with $\sqrt{N} / T^{2} \rightarrow 0$. 


\section{B. Cross-Sectional Dependence Test}

In order to determine the existence of cross-sectional dependence among states, we employ the simple tests suggested by Pesaran (2004). The Cross-Sectional Dependence (CSD) test statistics are based on the average of pair-wise correlation coefficients $\left(\hat{\rho}_{i j}\right)$ of the OLS residuals, obtained from the individual $\mathrm{ADF}$ regressions. The $C D_{P}$ test is given by:

$$
C D_{P}=\sqrt{\frac{2 T}{N(N-1)}\left(\sum_{i=1}^{N-1} \sum_{j=i+1}^{N} \hat{\rho}_{i j}\right)} .
$$

The $C D_{P}$ statistic under the null of cross-independence is distributed as a two-tailed standard normal distribution, i.e. $C D_{P} \sim N(0,1)$ for $T_{i j}>3$ and sufficient large $N$.

Since in our context we have relatively small $N$ and sufficiently large $T(T>N)$, we also, employ the scaled version of the Lagrange Multiplier (LM) test of Breusch and Pagan (1980), that is proposed by Pesaran (2004) and is based on the squares of the pair-wise correlation coefficients, that can be written as follows:

$$
C D_{L M}=\sqrt{\frac{1}{N(N-1)}\left(\sum_{i=1}^{N-1} \sum_{j=i+1}^{N}\left(T \hat{\rho}_{i j}^{2}-1\right)\right)} .
$$

which under the null hypothesis and following that $T \rightarrow \infty$ first and then $N \rightarrow \infty$ the $C D_{L M}$ statistic is asymptotically $N(0,1)$.

Baltagi et al. (2007) provide evidence that the general cross-sectional dependency test, $C D_{p}$, can be also employed as a useful diagnostic test for various models of spatial dependence.

\section{Panel Unit Root Tests}

Before proceeding with the panel estimation, we need to examine the order of integration of the series under consideration. We employ conventional univariate ADF tests (on the series that are not state specific) as well as the IPS panel unit root test of Im et al. (2003) and the CIPS panel test of Pesaran (2007) that takes into account cross-sectional dependence among panel members (on the state specific panel variables). 


\section{Panel Unit Root Tests without Cross-Sectional DePendence}

This panel test is an extension of the univariate ADF regression as follows:

$$
\Delta y_{i, t}=\alpha_{i}+\phi_{i} y_{i, t-1}+\sum_{j=1}^{p_{i}} \theta_{i, j} \Delta y_{i, t-j}+e_{i, t},
$$

where $y_{i, t}$ stands for each series under consideration for state $i$ at time $t$. The null hypothesis is that all series contains a unit root, $\phi_{i}=0$ for all $i$ (with $i=1,2, \ldots, N$ ), while the alternative hypothesis assumes that some of the $N$ panel units are stationary with individual specific autoregressive coefficients.

Im et al. (2003) propose a test based on the average of the ADF statistics computed for each individual in the panel. Specifically, the IPS statistic is defined as:

$$
\bar{t}_{N, T}=\frac{1}{N} \sum_{i=1}^{N} t_{i T}\left(p_{i}, \theta_{i}\right)
$$

Under the assumption of cross-sectional independence, this statistic is shown to converge to a normal distribution.

Panel Unit Root Tests with Cross-Sectional Dependence

The IPS test that is based on the restrictive assumption that the series are independent across states $i$, suffers from serious size distortion and restricted power in the presence of cross-sectional dependence (O'Connell, 1998) and cross-sectional cointegrating relationships (Banerjee et al., 2004). In order to overcome this, Pesaran (2007) proposes a simple approach to deal with the problem of cross-sectional dependence. A one-factor model is considered with heterogeneous factor loadings for residuals and suggests augmenting the standard ADF regression with the cross-section averages of lagged levels and first-differences of the individual series. The regression used for the $i^{\text {th }}$ cross-section unit is defined as:

$$
\Delta y_{i, t}=\alpha_{i}+\phi_{i} y_{i, t-1}+c_{i} \bar{y}_{t-1}+\sum_{j=0}^{p_{i}} \theta_{i, j} \Delta \bar{y}_{t-j}+\sum_{j=1}^{p_{i}} \theta_{i, j} \Delta y_{i, t-j}+e_{i, t},
$$


where $\bar{y}_{t-1}=N^{-1} \sum_{i=1}^{N} y_{i, t-1}$ and $\Delta \bar{y}_{t}=N^{-1} \sum_{i=1}^{N} y_{i, t}=\bar{y}_{t}-\bar{y}_{t-1}$. The CIPS test is based on the average of individual cross-sectionally augmented ADF statistics (CADF) as follows:

$$
C I P S=\frac{1}{N} \sum_{i=1}^{N} t_{i}(N, T)
$$

Simulated critical values of CIPS are listed in Pesaran (2007). Baltagi et al. (2007) show that the CIPS test is found to be robust to the presence of other sources of cross-sectional dependence such as the spatial form. 